\title{
Kernos
}

Revue internationale et pluridisciplinaire de religion grecque antique

18 | 2005

Varia

\section{Dans le nom, tout n'est-il pas déjà dit ?}

Histoire et géographie dans les récits généalogiques

\section{Pierre Brulé}

\section{(2) OpenEdition \\ 1 Journals}

\section{Édition électronique}

URL : http://journals.openedition.org/kernos/1530

DOI : $10.4000 /$ kernos. 1530

ISSN : 2034-7871

Éditeur

Centre international d'étude de la religion grecque antique

\section{Édition imprimée}

Date de publication : 1 janvier 2005

Pagination : 241-268

ISSN : 0776-3824

\section{Référence électronique}

Pierre Brulé, «Dans le nom, tout n'est-il pas déjà dit ? », Kernos [En ligne], 18| 2005, mis en ligne le 08 juillet 2011, consulté le 19 avril 2019. URL : http://journals.openedition.org/kernos/1530 ; DOI :

$10.4000 /$ kernos. 1530 


\title{
Dans le nom, tout n'est-il pas déjà dit? Histoire et géographie dans les récits généalogiques*
}

\begin{abstract}
Résumé : Nombre d'exégètes ont déjà montré comment le nom a fonctionné comme un tremplin pour donner à la pensée mythique grecque une impulsion particulière. Ces noms sont souvent "parlants », mais il en est de géographiques, ainsi celui d'Eurôpè dans ses rapports avec l'Europe. Eurôpè apparait plusieurs fois dans des récits généalogiques, et spécialement dans la Bibliothèque d'Apollodore. Elle est incluse dans des lignées, et sa présence leur donne tout leur sens. C'est l'occasion de revenir sur les qualités de ce cadre narratif minimum que constituent ces généalogies. Productrices d'un passé spécifique, elles ne donnent point l'Histoire : insuffisamment structurées et porteuses de valeurs extrinsèques. Elles sont aussi productrices d'espace. Les noms des acteurs de ces récits, par leur simple présence, et aussi par l'ordre dans lequel ils apparaissent dessinent une géographie qui est celle d'un cosmos fort remodelé par le caractère très narcissique de cette pensée, refermée sur son hellénité.
\end{abstract}

Abstract: Geography and History of genealogical accounts. Many scholars have already shown how names have functioned as a springboard giving mythic Greek thought a particular direction. These names are often "speaking" names, but some are geographic like that of Eurôpè in their relations with Europe. Eurôpè appears many times in genealogic accounts, and especially in Apollodore's Library. She is included in some lines and her presence gives them their entire signification. This provides the opportunity to return to this minimum narrative scope: the genealogic accounts. They give only a specific past, no history, because they are insufficiently structured and have outer values. They also give space. The names of the actors, simply by their presence, and also by the order in which they appear, draw a map, that of a cosmos, - but one remodelled by the highly narcissistic character of this thought, closed by its Hellenic conception.

\section{Prolégomènes}

À partir du III $^{\mathrm{e}}$ siècle av. J.-C., les collections de mythes ont connu une vogue. Des auteurs y ont rassemblé des mythes sans autre souci que de les grouper par thèmes. Parmi ces florilèges, les Katasterismes d'Ératosthène de Cyrène et son Astronomie poétique et Hygin avec ses Fabulae (II s. ap.). Le plus remarquable travail de ce type qui nous soit parvenu c'est celui dont on a longtemps pensé qu'il nous venait d'Apollodore ${ }^{1}$ : la Bibliothèque, du $\mathrm{I}^{\text {er }}$

* Avec de nouvelles perspectives, ce texte est le prolongement d'une conférence donnée dans le cadre d'un cycle de cours public organisé à l'Université Rennes 2 en 2003 par Catherine Guy et Guy Baudelle, "L'enjeu européen »; une version de cette conférence ("D'Eurôpè à l'Europe. Une invention bovine de l'Europe ») a paru dans le volume collectif, Le projet européen. Histoire, enjeu, prospective, Rennes, PUR, 2004, p. 25-34. Dans le débat sur la position de la Turquie par rapport à l'Europe il n'était pas inutile de montrer que les mythes grecs qui ont baptisé l'actuel «continent » liaient ce nom à une charmante personne... «asiatique », et que les limites passées comme actuelles des continents ne sont point affaire de détroit ou de montagne, mais d'histoire.

${ }^{1}$ Je me débarrasse du « Pseudo », tout le monde sait bien de qui je parle ici. 
siècle ap. J.-C. Il présente par rapport aux autres, cette particularité de lier entre elles des vies, des exploits dont d'autres sources font des morceaux indépendants. Sa forme générale et son fonctionnement obéissent au genre généalogique, si bien que l'auteur a même le souci de lier les lignées entre elles. C'est sur cette particularité généalogique que je fonderai en partie l'étude qui suit.

Photios présente l'ouvrage ainsi : «Dans le même volume ${ }^{2}$, j'ai lu un petit ouvrage d'Apollodore le Grammairien (grammatikos). Il a pour nom Bibliothèque. Il contenait les plus antiques récits des Grecs : tout ce que le temps leur a donné de croyances sur les dieux et les héros, ainsi que les noms des

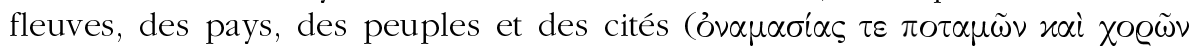

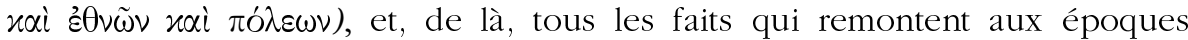
reculées ». Photios donne en peu de mots une bonne interprétation du fonctionnement de la Bibliothèque, en introduisant le temps comme facteur du façonnement des croyances (doxazein). Prenant dans ce qui suit cette interprétation au pied de la lettre, je vais faire mienne aussi son opinion selon laquelle, dans toute une classe de mythes, c'est à partir des noms (ó $\theta \varepsilon v$ ), des noms des choses : fleuves, pays, peuples et cités que les récits des Grecs

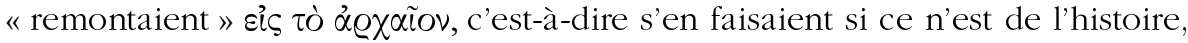
au moins du passé. Outre la question du nom et de la signification à accorder à la nomination ${ }^{3}$, cette différence entre passé et histoire, illustrée le plus souvent par le goût, l'intérêt, de cette culture pour la généalogie, sera l'objet de mon attention

Pour en revenir à Photios, il est plus qu'anecdotique qu'à son témoignage, l'exemplaire de la Bibliothèque qu'il a tenu entre ses mains portait une épigramme qui louait l'ouvrage pour l'érudition qui s'y trouvait déployée. C'est à cette érudition, dit-il, que nous devons de connaître les mythes

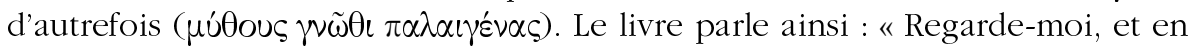

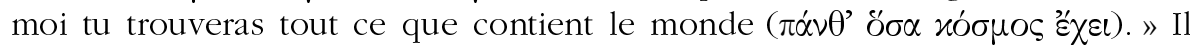
importerait évidemment de savoir si l'auteur de ce petit poème n'est pas Apollodore lui-même (alors, assez prétentieux), car cela apporterait plus de poids - un témoignage "vivant» - à ce qu'enseigne l'enquête philologique sur la Bibliothèque, à savoir qu'Apollodore n'est pas allé chercher les sources de cette mythographie (on peut s'entendre sur ce mot) dans le stock où s'approvisionnent de préférence les exégètes modernes, à savoir les poètes : Homère, les Hymnes, Hésiode, les Méliques, les Élégiaques, les Tragiques et les Cycliques, mais dans la prose, dans des ouvrages qu'on pourrait baptiser

${ }^{2}$ Qu'une édition des Narrationes de Conon (Photios, Bibliothèque, codex 146, 142 a-b; t. 3 de l'éd. d'Henri, CUF, p. 39-40).

3 Question déjà largement traitée que celle du nom comme " micro-récit »; sans chercher à tout citer: E. CASsIRER, Langage et mythe. À propos des noms de dieux, tr. fr., Paris, 1973. Cl. CALAME, "Récits et anthroponymes : noms de Laconiennes en figures de rhétorique », in $L e$ récit en Grèce ancienne, Paris, 1986, p. 153-161; N. LORAuX, "Poluneikes Epônumos : les noms des fils d'CEdipe, entre épopée et tragédie », in Cl. Calame (éd.), Métamorphoses du mythe en Grèce ancienne, Genève, 1988, p. 151-166; J. Svenbro, «AIAI. The Myth of Inscribed Flower » (communication au Colloque «Image and Word », University of Lund, oct. 1999). 
du nom d'«antiquités nationales », comme les Atthidographes: Phérécyde, Hellanicos, et leurs correspondants non attiques comme Acousilaos, comme Andron (cela, il le dit par défaut, mais ses lecteurs savants l'ont déjà relevé). Je suis encore plus persuadé de ce que j'écrivais sans originalité il y a dix ans : les choix opérés par l'auteur pour rédiger sa Bibliothèque font de celle-ci l'héritière des chroniques de cité. Outre l'apport de la Quellenforschung', il y a cette comparaison positive avec le contenu d'un document épigraphique datant du III siècle av. J.-C., le Marbre de Paros; tout cela invite à voir dans la Bibliothèque un document, certes sans prestige littéraire - privé des images et métaphores de la poésie -, mais unique en ce sens qu'il permet de retrouver comment on se racontait le passé, et spécialement les origines, dans les cités, au $\mathrm{IV}^{\mathrm{e}}$ siècle, et en particulier à Athènes. Il convient d'attacher à cette conclusion une grande valeur historique.

Donc, selon Photios, ces mythes (c'est le mot qu'il emploie), partent des

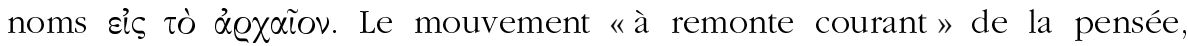
Photios n'en doute pas, part du matériau onomastique vers le passé, un passé indéfini. Il en va en l'occurrence du matériau onomastique comme, par exemple, des tombes mycéniennes qui, devenues pures structures, pures formes, sans raison d'être, sont réinvesties par l'imaginaire et retrouvent une légitimation, une justification par la grâce d'une histoire qui en explique l'origine; l'antériorité énigmatique se fait principe explicatif, et revêt un statut d'autorité : ce sont des tombes hérö̈ques. Cela illustre ce commun comportement de l'esprit humain qui peut partir d'un donné quelconque - d'une colline, d'un fleuve - pour lui associer une histoire où ils figurent, histoire qui justifie son existence et qui offre une possibilité d'interprétation du monde. Ce mécanisme psychique est avéré. Nous n'avons certes aucun moyen de vérifier que ce soit bien cette procédure mentale de l'induction qui fût à l'œuvre dans l'élaboration des récits que nous allons utiliser. Je poserai pourtant le même postulat: le nom constitue très souvent le matériau premier, la fondation indispensable au récit, récit qui, en retour et généralement en conclusion, justifie le nom. De sorte qu'on pourrait dire - en souriant! - que si on devait casser notre beau jouet en nous disant que non, décidément, le mythe, ça n'existe pas - il faudrait inventer une catégorie pour ces histoires grecques qui naissaient d'un nom et le justifiaient !

\footnotetext{
${ }^{4}$ Voici le texte du petit poème placé en exergue sur l'exemplaire de Photios : «Dans les spires du temps tu peux puiser grâce à mon érudition, et tu peux connaître les légendes d'autrefois. Ne va pas voir dans les pages d'Homère ni dans l'Élégie, ni chez la Muse tragique, ni dans la poésie mélique; ne cherche pas dans les vers bavards des Cycliques. Regarde-moi et en moi tu trouveras tout ce que contient le monde. " J'utilise la traduction qu'en ont donnée J-Cl. CARrière et B. MAssonie, La Bibliothèque d'Apollodore, Paris, 1991 (ALUB, 443), p. 25; c'est à cette édition que j'emprunte les traductions à venir, mais l'édition de référence est maintenant celle donnée par P. SCARPI, Apollodoro. I miti greci (Biblioteca), trad. M. G. CIANI, Fondazione Lorenzo Valla, Mondadori, 2000.

Voir surtout le très riche article de M. VAN DER WALK, « On Apollodori 'Bibliotheca' », REG 71 (1958) p. 100-168, le meilleur qu'on ait écrit sur la question.
} 


\section{Apparitions successives d'une Nymphe. Un nom qui nous rappelle quelque chose...}

Zeus confie son désir à Héra «Je n’ai jamais ressenti ça... Aucune, ni déesse ni femme » ne m'a fait cet effet; et Zeus y va de son palmarès de ses amantes ainsi supplantées : «ni Dia, ni Danaé, ni Sémélé, ni Alcmène, ni Déméter, ni Léto ». De ce catalogue des femmes que Zeus dit avoir aimées, mais qui ne valent pas Héra, j’en isole une : «la fille de l'illustre Phoïnix, qui [lui] donna pour fils Minos et Rhadamanthe, égal aux dieux» (Iliade XIV, $321)^{6}$. L'aède ne donne pas son nom, mais cette fille de Phoïnix est connue, c'est Eurôpè . Eurôpè, donc, comme une des séductrices de Zeus .

C'est curieux, non? Que cette aimée de Zeus porte le même nom que notre pseudo-continent. Cö̈ncidence homonymique? On n'y croit pas. On imagine tout de suite qu'il y a emprunt d'un domaine à l'autre. Que le mythe (c'est-à-dire la liaison Zeus - Nymphe) emprunte à la géographie ou l'inverse,

\footnotetext{
${ }^{6}$ Hésiode (et d'autres sources postérieures) nomment trois fils de Zeus et Eurôpè : Minos, Rhadamanthe et Sarpédon : fr. 140 (éd. MERKELbach/WeSt) et fr. 141 (dans les Ehoiai).

7 Par convention, la graphie Eurôpè désignera le personnage "mythologique » dans toutes ses «aventures » et dans tous ses états, alors qu'Europe désignera le continent, ou, quand le mot convient mal dans notre acception contemporaine, au minimum, une terre (pour la désigner on trouve aussi chôra).

Quelques appuis bibliographiques sur cette Europe. Ils sont particulièrement nombreux si l'on envisage aussi l'iconographie de l'enlèvement. Je me contente donc, sur ce sujet, de renvoyer à l'article de M. ROBERTSOn, s.v. «Europe» dans le LIMC IV.1 (1988) qui donne la bibliographie à jour jusqu'en 1988 à l'exception de H.R. HANke, Die Entführung der Europa. Eine ikonographische Untersuchung, Cologne, 1966; depuis M. Robertson a paru la thèse de O. WATTEL de Croizant, Les mosaïques représentant le mythe d'Europe ( $I^{e r}-V I^{e}$ siècles), Paris, de Boccard, 1995, qu'il faudrait n'utiliser qu'avec prudence (voir le compte rendu de C. LECOMTE, Kernos 10 [1997], p. 336-338). Sur le mythe principal et ses sources : W. Helbig, s.v. «Europa $10 »$, W.H. Roscher (éd.), Ausführliches Lexikon der griechischen und römischen Mythologie, I.1 (1884-1886), col. 1410-1418 (et d'autres Europe [1409-1410]); J. ERSCHER-BüRKLI, s.v. « Europe », RE VI.1 (1907), col. 1287-1298; A.B. CoOK, Zeus I (1914), p. 542-547, III (1940), p. 615-628; mention spéciale pour F.M. NINCK, Die Entdeckung von Europa durch die Griechen, Basel, 1946, et pour W. BüHLER, Europa, Munich, 1968 (il avait déjà donné une bonne étude de la source la plus riche : Die Europa des Moschos, Wiesbaden, 1960); P.B.S. ANDREws, «The Myth of Europa and Minos », GER 16 (1969), p. 60-66; Fr. DiEz DE Velasco, «Les mythes d'Europe », Métis 11 (1996), p. 123-132. Sur la fin de l'histoire il faut encore recommander le livre de Fr. Vian, Les origines de Thèbes. Cadmos et les Spartes, Paris, 1963. - Dans la perspective qui est la mienne, Eurôpè, ne m'intéresse pas « en elle-même ». Elle pourrait être remplacée par une autre. L'exercice le plus habituel des exégètes, qui consiste, à partir de renseignements de natures très différentes, à recomposer une Eurôpè, " retrouvant» dans ce soi-disant "personnage», soit une Sémite, soit une Béotienne (L PRANDI, «Europa e i Cadmei : la 'versione beotica' del mito », in L'Europa nell mondo antico, o.c. [n. 9], p. 37-48) ou une nymphe multifonctionnelle : «sposa, madre, regina » (D.M. Cosi, « Dietro al fantasma di Europa : sposa, madre, regina », ibid., p. 27-36)..., cet exercice n'est pas le mien ici; Eurôpè ne m’intéresse que comme éponyme de l'Europe et comme élément dans des généalogies. Et si, abandonnant cet aspect des choses pour celui du culte, on y cherche une unité, on n'en trouvera pas plus dans une Eurôpè, à Gortyne, liée à un cours d'eau et à un platane (Théophraste, Hist. des plantes I, 9, 5, cf. Pline, H.N. XII, 11) et une Eurôpè, à Lébadée, qui n'en est pas une puisque ce nom n'apparaît que comme une épiclèse de Déméter (Pausanias, IX, 39, 4).
} 
que le nom d'une des amantes joviennes a servi ensuite à désigner une terre. Mais qu'est-ce que ça veut dire, ensuite ? Comment construire de tels rapports chronologiques? Et puis, si c'était vérifiable, comment, alors, serait-ce devenu «notre » nom, celui qui était déjà utilisé certainement au vI siècle, mais très probablement avant, pour désigner un continent? Comment prendre l'alternative : faut-il penser qu'il n'est de terre qu'ayant un nom, et qu'un nom existe en même temps qu'existe la terre, faut-il penser que ce nom fût d'abord celui d'une jeune fille avant qu'on appelle cette terre-ci d'après elle ou qu'une jeune fille prend le nom d'une terre (déjà là) parce que son histoire lui est liée. Dans les récits qui nous viennent des Grecs en tout cas, quand un personnage (homme ou, plus souvent, femme) apparait dans une histoire, avec des ascendants et des descendants, quand ce personnage voyage, qu'il porte un certain nom, agissant, ou simplement étant, cela suffit à baptiser le lieu où il se trouve ou s'installe. C'est ce versant de l'alternative qui se conforme à la plus constante procédure étymologique grecque, et qui rend compte aussi du constant fonctionnement des mythes. C'est précisément ce qu'en dit un spécialiste quand il s'agit d'Europe, Moschos.

\section{Un rapt érotique comme déclencheur}

\section{Des noms : la Nymphe et les épires}

Chez Moschos (L'enlèvement d'Europe, II ${ }^{\mathrm{e}}$ av. J.-C.), dans le songe, prémonitoire bien sûr, qu'envoie Aphrodite à la parthénos, Eurôpè découvre deux terres (deux "épires», deux «continents») : «la terre d'Asie (où elle se trouve) et la terre d'en face » (Asida t'antiperèn te). Une èpeiros existe donc d'emblée, qui a un nom. Anticipant sur la suite, on dira que l'Europe vient d'Asie. Dans le songe d'Eurôpè, l'autre, l'antiperan, est anonyme, donc elle n'existe pas. Il est dans la logique narrative qu'Eurôpè - plus exactement, son nom -, soit «en réserve » de l'explication étymologique à venir. Ces terres se disputent Eurôpè elle-même (v. 8). "L'une a une xeniè morphè », l'autre est une femme du pays qui prenait bien soin d'elle. Mais celle aux traits d'étrangère, la saisissait vivement pour l'emporter en disant que c'est «la volonté de Zeus..., [qu']il a décidé qu'Eurôpè lui appartiendrait» (v. 14-15). L'Europe, c'est donc bien une terre détachée de l'Asie. L'Asie est antérieure à l'Europe, qui existe par la volonté de Zeus, c'est une articulation chronologique. Le songe s'accomplit. Enlevée par Zeus, Eurôpè abordera cette curieuse èpeiros d'en face qu'est la Crète; on ne sache pas que jamais elle lui ait donné son nom, ce qui ne se conforme pas aux règles habituelles de ces récits : l'éponymie du nom de la Nymphe qui explique, par exemple, le nom de Cyrène'. Toutefois, la geste d'Eurôpè ne s'arrête pas là.

Mais, n'est-ce pas là qu'une reconstruction «mythologique » ? Je veux dire par là simplement : ce récit ne cherche-t-il pas une réponse à une question

9 Cl. CALAME, Mythe et Histoire dans l'Antiquité grecque: la création symbolique d'une colonie, Lausanne, Payot, 1996. 
qui n'en a pas? Se demander pourquoi Rennes s'appelle Rennes. C'est de la métaphysique, ça! Pourquoi Héra s'appelle-t-elle Héra et l'Europe, Europe ? La matière même des textes, d'ailleurs, nous dissuaderait de poser ainsi la question (de la Nymphe donnant son nom à un lieu, auparavant sans nom). Nous sommes en effet certains qu'en cette occurrence au moins l'hypothèse est fausse. On ne peut pas dire dans ce cas qu'un nom de personnage divin ou mythologique "préexistant» ait servi ensuite à désigner un continent. En effet, dans l'Iliade, l'amante anonyme du dieu est dite "fille de Phoïnix » (Phoinikos kourè) (Moschos est plus précis : Phoinikos thugater eti parthénos). Cela permet de l'identifier à coup sûr; en effet, entre les deux Phö̈nix connus, on ne peut hésiter: le père de la partenaire sexuelle de Zeus n'est pas le précepteur d'Achille, c'est l'éponyme des Phéniciens et/ou de la Phénicie. Europe est donc fille d'un lieu ou d'un peuple. Dans la conception grecque des récits généalogiques qui fabriquent de l'espace et du temps (infra), le nom est d'emblée géographique, même s'il désigne aussi une amante d'un dieu. Ce qui donc est premier, c'est le lieu (ou le peuple), tout en tenant compte du fait que la princeps désignation - au sens transparent - nous donne un nom de jeune fille. Simplement un nom. Voyons-le un peu.

\section{Son nom ${ }^{10}$}

Pas question pour moi d'entrer dans une controverse à propos de l'hypothèse d'une étymologie sémitique, je n'en suis pas capable et, même si le fait devait être avéré, ce qui m'intéresse, c'est la réception du mot non sa préhistoire $^{11}$.

Eurôpè, c'est le même nom - accentué sur l'antépénultième - que celui que, dès l'Hymne à Apollon (251 et 291), on donne à l'épire grecque (ce qui

10 Outre les répertoires habituels, H. FRISK, Griechisches etymologisches Wörterbuch I, Heidelberg 1960 et III, 1972, s.v. et P. Chantraine, DELG, 1968-1980, s.v., il faut renvoyer à B.W.W. DOMBrowski, Der Name Europa auf seinem griechischen und altsyrischen Hintergrund, Amsterdam, 1984, dans L'Europa nel mondo antico, a cura di Marta Sordi, CISA 12 (1986), p. 3-11 et 12-26 (abrégé infra en Europa nel mondo antico), aux mises au point de C. MiLANI, " Note etimologiche su Eurôpè » et de F. Luciani, «La presunta origine semitica del nome Europa », toutes deux); C. MiLANi y revient dans «Questions étymologiques d'Europe et de l'Europe », in R. Poignault, O. WatTEl-DE Croizant (éds), D'Europe à l'Europe. I. Le mythe d'Europe dans l'art et la culture de l'Antiquité au XVIII siècle. Actes du colloque tenu à l'ENS, Paris (24-26 avril 1997) Centre de Recherches A. Piganiol, Tours, 1998 (Caesarodunum, 31bis), p. 31-37; je n'ai pas pu consulter G. RESTELLI, «La glossa di Eschilo eurôpis : hè patris. Ricostruzione del testo e connessioni storico-culturali ", Linguistica nuova e antica 1 (1983), p. 91-105. La question est indirectement liée à celle de l'origine de Cadmos. On en a beaucoup débattu et la bibliographie croît avec le temps, sans qu'on puisse dire qu'on s'approche d'une conclusion : VIAN, o.c. (n. 8), p. 31-35; L. PRANDI, «Europa e i Cadmei : la 'versione beotica' del mito », in L'Europa nell mondo antico, p. 37-48; P.H. GOMmers, Europe - What's in a name?, Leuven, 2001; les dernières traces de la polémique à propos des rapports de Cadmos avec la Phénicie dans R. BEEKEs, «Kadmos and Europa, and the Phoenicians », Kadmos 43 (2004), p. 167-184 qui bataille contre K. MEISTER, s.v. « Kadmos », Der neue Pauly VI (1999) col. 129-131..

${ }^{11}$ Qu'al-kohl désigne de l'antimoine pulvérisé n'a rien à voir avec l'association que je fais entre l'alcool et l'ivresse ! 
la distingue des îles et du Péloponnèse $)^{12}$, c'est celui qu'utilise fin vI ${ }^{e}$ siècle Hécatée de Milet dans sa Périégèse reconstituée essentiellement à partir des citations de Stéphane de Byzance. C'est un nom de lieu au nord du golfe de Corinthe (Eurôp- ou Europ-). En Macédoine c'est le nom de deux villes, dans le Pénée, une ville et une rivière ${ }^{13}$.

Ce nom apparaît d'abord comme "normal», même s'il n'est pas très attesté. Le premier élément, eur-, de eurus: 'large', 'vaste', entre en composition dans des noms de personne (Euryalos; Euryptolémos) ou de lieu (Eurymédon); second élément, ôps, -ôpos 'œil', 'vue', d'où 'visage', d'où 'large visage', 'beau visage'. Ce composé apparaît dans des adjectifs (kèkrôpè), et est fréquent dans les toponymes (Sinôpè, Parthenopè...). Le problème, c'est que la disparition du $u$ ne s'explique pas.

Il y a doute, et c'est ce qui incite P. Chantraine à proposer de considérer comme indépendants l'un de l'autre le nom de la Nymphe et celui du continent, se demandant si ce dernier "n'est pas issu de l'adj. eurôpós " ${ }^{14}$, accentué sur la finale. Il donne à cet autre dérivé d'eurus le sens de 'large', renvoyant à Euripide. Or, si cet autre eurôpós apparaît bien chez le Tragique, et aussi chez Oppien et Hésychios, son sens en ces occurrences nous met sur une autre voie. Hésychios donne comme synonyme skoteinos: 'obscurité'; dans l'Iphigénie en Tauride (625-6) comme dans Les halieutiques (III 18 s.), le contexte de son emploi renvoie aussi à cette idée d'obscurité; et l'on voit bien comment on passerait de cette obscurité à 'vespéral' et de 'vespéral' à 'occident' et de là à une terre ${ }^{15}$. Là où l'on retrouverait la cosmographie...

C'est une époque très ancienne que celle où fut chantée d'abord cette tromperie de Zeus ${ }^{16}$ - Apatè Dios - où le nom d'Eurôpè apparaît pour la première fois, une Europe fille d'un Asiatique, selon nos catégories géographiques! Mais tout le monde ne partage pas cette généalogie. Passant du premier texte à son suivant, d'Homère à Hésiode, le contexte est tout autre. Dans sa Théogonie, Eurôpè figure au sein de la profuse descendance d'Océan

\footnotetext{
12 Cf. aussi, dans les sources du ves., Eschyle, fr. 191 SIDGwICK; Pindare, Ném. IV, 70 et surtout Hérodote ( $c f$. infra, p. 267). Le IV ${ }^{e}$ s. voit l'élargissement de la conception géographique de l'Europe dans le cercle d'Isocrate, on verra sur cette question C. BEARZOT, "Il significato della basileia tès pasès Eurôpès nell 'Encomio di Filippo' di Teopompo ", L'Europa nell mondo antico (o.c. [n. 10]), p. 91-104. On trouve aussi Eurôpia dans des titres d'œuvres perdues, chez Sophocle (fr. 39) et chez Euripide (Thésée, fr. 1 [éd. JOUAN - VAN LOOY]). C'est le nom d'une source chez Pindare, Péans, fr. 70, 2. Il existe des cités appelées Europos, diversement accentuées, en Macédoine et en Syrie (en réalité, un seul exemple puisque cette ville de Syrie, c'est Doura sur l'Euphrate, appelée Eurôpos parce que Séleucos était né à Eurôpos en Macédoine).

13 Les sources chez F.M. NincK, l.c. (n. 8), p. 17 (carte p. 16).

14 O.c. n. 10 , p. 388.

15 Je suis Milani, o.c. (n. 10), p. 10

Il faut aussi insister sur l'ancienneté des représentations figurées : voir les métopes de Delphes et de Sélinonte qui sont respectivement datées de 560 et de 550.
} 
et Téthys (357 sq.). De ce couple prolifique sont issus des principes masculins : - les Fleuves «à l'onde tourbillonnante», cela va de Nil à Scamandre ${ }^{17}$; puis féminins: tout un inventaire de Nymphes, de déesses, d'héroïnes : Ouranie, Dionè l'adorable, Calypso, la très désirable, mais aussi Asiè, et notre Eurôpè, et... «trois mille Océanides aux fines chevilles, peuplent des lieux nombreux, brillantes enfants des déesses, éparpillées sur terre et au fond de l'onde marine » (361-365). Voilà donc sœurs nos deux éponymes continentales. Par ailleurs, dans son Catalogue des femmes, qui nous est parvenu en lambeaux, dans une des guenilles citée par une scholie, le même Hésiode évoque notre Nymphe - cette fois, «en situation »: «Zeus, voyant Eurôpè fille de Phoïnix, cueillant des fleurs dans la prairie avec des Nymphes, fut saisi d'amour. Il descendit et se changea en taureau dont la bouche exhalait une odeur de safran. C'est ainsi qu'il trompa Eurôpè et l'emporta en Crète et s'unit à elle. Ainsi, ensuite, il la donna en mariage à Astérion, roi des Crétois. Devenue grosse, elle enfanta trois fils, Minos, Sarpédon et Rhadamanthe. Cette histoire se trouve chez Hésiode et Bacchylide " ${ }^{18}$. Retournons donc sur la rive phénicienne pour cet épisode du rapt qu'on ne peut passer sous silence.

\section{Enfants, voici les boufs qui passent, cachez vos rouges tabliers...}

Comment passer vite sur ce qui, dans cette histoire, relève du «comment? », il y a tant à dire, aussi vais-je citer longuement Moschos. La scène se passe à Tyr $^{19}$ ou à Sidon ${ }^{20}$. La princesse, thygater eti parthenos, s'est levée après avoir fait le rêve signifiant rapporté plus haut ${ }^{21}$.

Elle alla chercher ses compagnes nobles filles de son âge, nées la même année qu'elle, qui plaisaient à son cour et étaient associées à tous ses jeux, qu'elle se préparât pour un chœur de danse, qu'elle lavât son corps à l'embouchure des rivières, où qu'elle cueillît dans la prairie les lys à l'haleine parfumée... Elles gagnèrent les prairies voisines de la mer, qui étaient le lieu de réunion habituel de leur troupe, charmée par la beauté des roses et par le bruit des flots. Eurôpè ellemême portait une corbeille d'or magnifique, admirable merveille, admirable travail d'Héphaïstos; il l'avait donnée à Libyè, quand elle était entrée dans le lit

17 Cette eau fluviale que nous retrouverons.

Schol. Iliade XII, 292 = Hésiode fr. 140 (éd. M.W.). Voir aussi fr. 141 = Bacchylide fr. 10 (éd. SNELL)

19 Déjà Hérodote, I, 2, 2 et IV, 45, 4.

${ }^{20}$ Hygin, Fab., 178, 1; comme le commente, W. BüHLER, Europa, o.c. (n. 8), p. 10, les désignations de Sidonienne ou de Tyrienne qu'emploient des sources tardives ne renvoient pas à un «ethnique» précis, mais à des synonymes de Phénicienne. Un passage du roman d'Achille Tatius, Le roman de Leucippé et Clitophon fait une distinction entre terre et mer: le héros, «visitant la ville et regardant les offrandes,... [vit] un tableau consacré figurant à la fois la terre et la mer : c'était la représentation d'Eurôpè; la mer était celle des Phéniciens, la terre celle de Sidon... » (I, 2-3, trad. J.-Ph. GARNAUD, CUF).

21 C'est la traduction de Ph. E. LEGRAND dans la CUF. 
d'Ennosigaios; Libyè l'avait donnée à la toute belle Tèléphassa, qui était de son sang; et Tèléphassa avait remis ce superbe présent à Eurôpè non mariée ${ }^{22}$. Arrivées dans les prés fleuris, les jeunes filles se divertissaient à chercher chacune telle ou telle sorte de fleur; l'une prenait le narcisse odorant, l'autre l'hyacinthe, celle-ci la violette, celle-là le serpolet... Elles coupaient ensuite, luttant à qui en couperait le plus, les touffes parfumées du jaune safran. Mais la princesse, cueillant à pleines mains (?) les roses resplendissantes à la couleur de flamme attirait parmi elles les regards comme parmi les Charites la déesse née de l'écume. Elle ne devait pas longtemps prendre plaisir à des fleurs, ni conserver intacte sa ceinture virginale (parthenièn mitrèn achranton). Aussitôt que le fils de Cronos l'eut aperçue, de quel vertige saisi il fut dompté par les traits imprévus de Kypris, seule capable de dompter Zeus lui-même !... [Il se transforme en taureau.] Il vint dans la prairie, et son apparition n'effraya point les jeunes filles; toutes furent prises du désir de s'approcher, de toucher le joli animal, dont la divine odeur, se répandant au loin, dominait même le souffle embaumé de la prée. Il s'arrêta en face de l'irréprochable Eurôpè; il lui lécha le cou et la jeune fille fut sous le charme. Elle le flatta... lui donna un baiser. Lui, poussa un tendre mugissement, on aurait cru entendre résonner la flûte mygdonienne. Il s'agenouilla aux pieds d'Eurôpè... «Venez, chères compagnes,... asseyons-nous sur ce taureau... Elle dit, et elle s'assit sur le dos du taureau, souriante; et les autres filles allaient en faire autant; mais il se releva d'un bond, enlevant celle qu'il voulait, et gagna rapidement la mer... Le taureau parvint au rivage et poursuivit sa course, comme un dauphin, marchant sans mouiller ses sabots sur la vaste étendue des vagues ${ }^{23} \ldots$ Déjà apparaissait la Crète; par un nouveau changement, Zeus reprenait sa figure; il délia la ceinture d'Eurôpè; les Heures lui préparaient sa couche; elle, qui était vierge auparavant, sans tarder devint la nymphe de Zeus, sans tarder conçut des enfants du fils de Cronos et devint mère (?).

On dira que ce poète affectionne de peindre les décors champêtres, les ébats de la jeunesse, spécialement les vierges, qu'il ne manque pas d'imagination, on lui reconnaîtra un goût pour un cadre topographique et végétal original : une prairie au bord de la mer, jusqu'à un univers olfactif précis et défini... Désolé, pour lui et pour d'autres, mais, pour qui a fréquenté les jeunes filles avec leurs fleurs dans la littérature grecque, rien de tout cela n'est original. Des vierges batifolant dans des prairies, cueillant des fleurs, com-

22 Un développement ultérieur (vers 43 - 62) décrit la corbeille; on y voit Io, fille d'Inachos, " encore génisse », " marchant sur les chemins de la plaine salée »; Zeus, « effleurant doucement de la main la génisse... qu'auprès du Nil à sept bouches, de vache cornue, de nouveau il transforma en femme; le cours du Nil était d'argent... ».

${ }^{23}$ Chez Nonnos, la scène est autrement suggestive : "(Zeus) laisse sa forme de taureau et, sous les traits d'un jouvenceau, le voici qui court autour de la vierge indomptée (azyga kourè). Il la caresse, commence par dénouer sur la poitrine de sa fiancée la ceinture (mitrè) qui lui serre la taille, presse comme par mégarde les contours arrondis de sa gorge ferme, effleure sa lèvre d'un baiser. Puis, en silence, rompant le chaste lien qui préserve son intégrité virginale (hagnon anympheuton), il cueille le fruit encore vert des amours de Cypris» (Dionysiaques, scène du rapt : I 46-137, et 322-355 pour la scène érotique; trad. Fr. Vian [CUF]). 
plexe qui, par la grâce d'Aphrodite, a pour effet de voir apparaître un masculin-rapteur - ici, bovin -, cela touche à la rengaine ${ }^{24}$.

Au palmarès de ces enlèvements, la figure la plus remarquable, c'est celle de Korè ${ }^{25}$. Elle «'joue' avec les jeunes Océanides à l'ample poitrine (selon Hésiode, Eurôpè en est une) et 'cueille des fleurs ${ }^{26}$, des roses, du safran et des violettes, 'dans une tendre prairie', - des iris, des jacinthes et aussi le narcisse, qui brille d'un éclat merveilleux. Elle étend ses deux bras pour le saisir, « mais la terre aux vastes chemins s'ouvre dans la plaine nysienne, et il en surgit, avec ses chevaux immortels, le "Seigneur de tant d'hôtes », Hadès. "Il l'enlève et l'entraîne malgré sa résistance tout en pleurs sur son char d'or. » Que je te cueille, que je te vois, que je t'enlève...

Un leitmotiv, une image mentale qui s'impose à tous pour dire à la fois qu'il y a une jeune vierge désirable et un désir, humain ou, plus souvent, surhumain. On inverse les priorités. Dans le fonctionnement du récit, la vierge n'est là que pour que se manifeste le désir masculin (car c'est la suite qui compte); dans la chair du récit, on ne parle que d'elle, le désir masculin est second (non secondaire). Comme les autres, Eurôpè est fille de son père, fille de roi ou de dieu. Elle est pubère et vierge, non-mariée (anymphôi). Belle, donc désirable ${ }^{27}$. Pour mieux sertir ces filles il faut un écrin. C'est le chœur : "toutes de même âge », "ses amies ${ }^{28}$, les cinquante Océanides à l'ample poitrine ». Si Nausicaa, c'est Artémis au milieu de ses compagnes, Eurôpè c'est Aphrodite au milieu des Charites. Dans ce monde aride de la Méditerranée orientale, elles jouent dans une prairie au bord d'un cours d'eau ou de la mer, ou les deux ${ }^{29}$. Elles cueillent des fleurs. C'est une anthologie. On aurait tort de se laisser guider par nos appréciations et de n'y voir qu'une occupation

${ }^{24}$ Voyez Hélène, qui cueille des roses pour Athéna et les dépose dans les plis de sa robe : Hermès l'enlève (Euripide, Hélène, 240). Agriabè se promène avec ses servantes dans les prés de son père : son amoureux l'enlève (Parthenius, Narr. Amor., 26). La mieux connue sans doute de ces scènes d'anthologia ne comporte pas d'enlèvement. C'est celle d'Ulysse naufragé, nu, sur une plage de Phéacie face au chøur de Nausicaa et de ses servantes, qui, la lessive du palais finie, jouent à la balle sur la grève. Sur les filles en fleur en chœurs : A. MOTTE, Prairies et jardins dans la Grèce antique, Bruxelles, Académie royale de Belgique, 1973; Cl. CALAME, Les chœurs de jeunes filles en Grèce archä̈que, Rome, Ateneo, 1977 et les chapitres VIII et IX de L'éros en Grèce antique, Paris, Belin, 1996; P. Brulé, La fille d'Athènes, Paris, Les Belles Lettres, 1987, 289-290; 296-300 et A. Bonnafé, Poésie, nature et sacré, 1 et 2, Paris, de Boccard, 1984/1987.

25 Hymne à Déméter, 5-19.

26 Parallèles «européens » : sch. Iliade XII 292 (anthè legousan); Ovide, Métam., II 845; mythographe du Vatican, I, 148..

${ }^{27}$ Sur ce complexe de la 'beauté', qui est celui du modèle de la canéphore, je me permets de renvoyer au chapitre 3 de La fille d'Athènes, o.c., 1987, spécialement p. 301-308.

${ }^{28}$ Ovide, ib.; Ach. Tat., I, 1, 6-7; Lucien, Dial. Mar., 15, 2 ..

29 Et une autre image vient alors s'associer à ce décor, à ce féminin du bord de mer : le danger d'enlèvement, de rapt; voir ce qui arrive aux filles/femmes kidnappées par des pirates, des brigands, des étrangers, au Pirée, à Brauron et ailleurs (Brulé, La fille d'Athènes, o.c., p. 287, 289-300 et 305-306 et "Hyménée sonore : La musique du gamos », in P. Brulé et Chr. VENDRIEs (éds), Chanter les dieux. Musique et religion dans l'Antiquité grecque et romaines, Rennes, PUR, p. 251-253). 
insignifiante. Elles ne cueillent pas n'importe quoi. Toujours reviennent les mêmes fleurs. Au palmarès l'emportent la rose, le safran (ou crocus), la violette. Tout débutant botaniste y remarque la fréquence des liliacées monocotylédones (crocus, jacinthe, narcisse, iris).

Miroirs de la beauté des filles, ces fleurs parlent d'elles, encore. Mais n'allons pas trop loin dans cette direction de préciosité : quel rapport avec le surgissement du désir masculin? Le parfum est indispensable à l'érotique grecque. Rose et safran sont les principales fragrances aphrodisiaques des Grecs. Le bovin lui-même emprunte à ce pouvoir, et c'est ce qui séduit la demoiselle... On racontait qu'Eurôpè «avait été saisie de folie (emanè), fut prise d'un amour violent (pany erôtikôs) à cause des roses que sentait le taureau qui l'enleva. D'autres ont dit qu'il exhalait par les naseaux une odeur de safran $»^{30}$. L'exégète moderne joue sur du velours avec cette figure grecque du rapt érotique, à la signature structurale si claire. Mais il reste encore beaucoup à éclairer. Cette histoire d'Eurôpè est traversée par d'autres thématiques.

\section{D'histoire en géographie}

Un passage du récit de Moschos n'a pas reçu de commentaire. Le talaros (une des nombreuses 'corbeilles' des Grecs...) dans lequel Eurôpè dépose ses fleurs a été fabriqué par Héphaïstos, qui «l'avait donné à Libyè, quand elle était entrée dans le lit d'Ennosigaios; Libyè l'avait donné à la toute belle Tèléphassa, qui était de son sang; et Tèléphassa avait remis ce superbe présent à Eurôpè non mariée ». Ce talaros suit un parcours qui va de Poséidon (Ennosigaios) à Rhadamanthe, se mariant correctement à la généalogie et conforme aux indications que donne la Bibliothèque (qui s'y connaît).

Comme nous l'avons dit, Libyè eut de Poséidon deux fils, Bèlos et Agènor. Bèlos régna sur les Égyptiens et engendra les fils dont il a été question plus haut. Agènor, parti en Phénicie, épouse Tèléphassa et engendre une fille, Eurôpể, et des fils, Cadmos, Phoïnix et Kilix.... Zeus, saisi d'amour pour elle, prit la forme d'un aimable taureau à l'haleine de rose et, lorsqu'elle fut montée sur son dos, il l'emporta en Crète à travers la mer. Là, Zeus s'unit à elle et elle enfanta Minos, Sarpédon et Rhadamanthe... (III, 2)

Cela donne la généalogie suivante :

30 C'est dans le commentaire d'Eustathe (Iliade, s.l. XIV, 213, éd. VAN DER VALK, III, p. 654) qui explique le nom de Rhadamanthe par le fait que sa mère fut saisie de folie; le safran encore dans le fragment déjà cité (supra n. 17) d'Hésiode et Bacchylide.

${ }^{31}$ W. BüHLER (o.c. [n. 8]), remarque justement qu'aucune source ne donne Agènor comme père d'Eurôpè avant le $\mathrm{I}^{\mathrm{er}}$ s. av. J.-C.; on a d'abord Varron, L. l., 5,32 puis (entre autres) Ovide, Métam. II, 858; Diod., V, 78, 1; Hygin, Fab., 155, 2 et 178, 1...; toutefois, évidemment, les données de la scholie à Euripide, Phén., 217, peuvent être empruntées à une source plus ancienne; quant à la scholie au vers 29 du Rhésos, elle rapporte que, selon Euripide, Eurôpè est fille de Phoïnix fils d'Agénor; enfin le fait que Cadmos, fils d'Agènor, soit parti à la recherche d'Eurôpè, n'implique-t-il pas qu'elle soit sa sœur? Or cette information se trouve pour la première fois chez Hérodote (IV, 147, 4). 


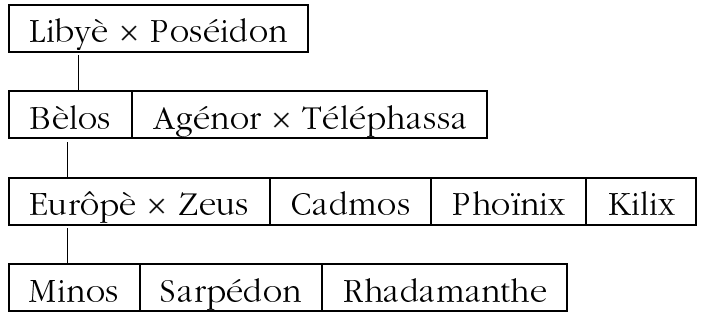

La Bibliothèque glisse en outre ceci : "Certains auteurs, toutefois, disent qu'Eurôpè n'est pas fille d'Agènor, mais de Phoïnix ». Nous en connaissons au moins deux de ces auteurs, ce sont Homère et Hésiode! C'est chez eux d'abord que nous avons rencontré cette parthénos, comme fille de Phoïnix. Et ce n'est certes pas la même chose qu'Eurôpè soit fille de l'un ou de l'autre, faisant de la Nymphe selon le cas une Asiatique ou une Africaine et de l'Europe une èpeiros d'origine phénicienne ou libyenne.

Chemin faisant, nous venons donc de découvrir un troisième nom géographique : à la Phénicie et à l'Europe s'est ajoutée la Libye. On ne trouve pas trace dans la Bibliothèque d'un détail fondamental la concernant et que l'auteur aurait pu puiser au moins chez Hérodote : «La Libye..., disent la plupart des Grecs, serait ainsi dénommée d'après Libyè, une femme autochthone; l'Asie aurait pour éponyme la femme de Prométhée » (IV, 45). Ce n'est pas le premier cas de ces femmes qui donnent leur nom à une terre et qui sont « du pays » : il y avait déjà celle, si gentille, qui figurait la terre d'Asie qui prenait bien soin d'elle. Contrairement à ce que la masse des études sur l'autochothonie, trop focalisée sur le cas athénien, laisse supposer, l'ancêtre autochthone (au moins l'un d'eux) est souvent féminin ${ }^{32}$.

Ce qui motive mon recours à la Bibliothèque, c'est que j'y puise la matière pour compléter cette généalogie en morceaux. C'est qu'à la manière des stratégies tout humaines de la dation des noms dans une famille, on voit combien, dans nos textes, la distribution des noms revêt une valeur hautement symbolique, comme elle invite à faire de l'histoire et de la géographie.

Les questions ne manquent pas. Que fait Eurôpè en Phénicie ? Pourquoi la Crète comme but du voyage de noces ? Comment prendre cette île pour un continent? Que signifient ces régions - l'Europe, l'Asie, la Libye - pour les Grecs à l'époque de telle ou telle source ? Peut-on donner sens à l'identité d'Eurôpè : fille de Phoïnix, lui-même fils de Libyè ? Chercher des réponses à ces questions, c'est quitter le mythème du conte bleu, la mise en scène obligée des jeunes filles en fleurs au bord de l'eau pour tenter de s'approcher de l'Eurôpè que nous connaissons, c'est-à-dire de l'Europe. Avec cette

32 Voir dans Poikilia (1996), respectivement, p. 7-17 et p. 17-6, M. COCHET, « L'autochtonie chez Pausanias : modèle ou exception athénienne? » et E. CHEminel, «La jeune fille et le héros autochtone ». 
question du père de la fille et du père du père de la fille, c'est de celle de la reproduction, de la dation des noms, du mariage, des errances donc de l'espace, enfin de celle du temps dont on va parler.

Dans son cartésianisme "naturel», l'historien moderne distingue inévitablement le temps de l'espace, deux concepts que, dans ces récits généalogiques, les Grecs ont intimement mariés. En même temps qu'ils évoquent des régions du monde, ces récits répondent aux mêmes questions : qui succède à qui ou qui engendre qui et comment? Qui est en famille avec qui, de qui descend celui-ci ? Un commun savoir comme en manient avec dextérité les sociétés paysannes, où tout un chacun connaît la situation de telle ou telle héritière. De sorte que le locuteur n'a même pas besoin de dire d'où il prend le renseignement ni - parlant d'un maillon quelconque de la chaîne généalogique - de rappeler ce qui précède et ce qui suit.

\section{Le temps}

Enchaînant chronologiquement les générations, ces récits fabriquent du temps et cette «fabrication» revêt des aspects à la fois «archaïques » et « modernes ».

Archä̈que, cette façon de mêler fiction et réel. Un exemple parallèle bien connu est fourni par une fameuse inscription d'Halicarnasse malheureusement perdue $^{33}$. On sait qu'il s'agit d'une liste énumérant chronologiquement des prêtres de Poséidon Isthmios, elle-même copie d'un document plus ancien (ek tès archaias stèlès) qui se présente en deux colonnes, la seconde étant contemporaine de la regravure que R. Descat date du III siècle $^{34}$. Les noms des prêtres sont répertoriés à partir du fondateur (apo tès ktiseôs) qui venait de Trézène (1. 6) et qui, d'après ce document ${ }^{35}$, n'est autre que Télamon le fils de Poséidon. Sans doute viagère, la prêtrise appartient à la catégorie des prêtrises

33 Syll. ${ }^{3}, 1020$.

R. DESCAT ( À propos d'un citoyen de Philippes [nouveau nom donné à Euromos par Philippe V] à Théangéla », REA 99 [1997], p. 411-413) parvient à ce résultat grâce aux recoupements possibles avec d'autres documents et que permet la présence d'un Politès à Théangéla et dans liste de la seconde colonne (voir plus loin) ( $c f$. A. WILHELM, «Inschriften aus Halikarnassos und Theangela », JOAI 11 [1908], p. 53-75, spéc. 63 et 67).

Je m'exprime ainsi parce que le doute est permis. En effet, comment ne pas rapprocher cette liste du récent texte de Samalkis célébrant les honneurs d'Halicarnasse (S. ISAGER, "The Pride of Halicarnassos », ZPE 123 [1998], p. 1-23) ? On y cherche pourtant en vain Télamon. Il est vrai que la partie consacrée aux fondateurs (1. 31 et suivantes) avec un ou deux mot(s) par ligne est en pauvre état. Il n'est néanmoins pas impossible que ce soit lui qui soit mentionné à la ligne 31 où l'on a : [-----------Posid]ônios huios. Il est aussi troublant de relever le nom d'Anthas à la 1.7 de la liste des prêtres, alors que le fondateur de la cité est appelé Anthès (Pausanias évoque ainsi les antécédents de la fondation d'Halicarnasse : "Quand Trézène mourut, Pittheus rassembla les habitants ensemble, incorporant Hyperea et Anthea dans la nouvelle cité qu'il appela Trézène d'après son frère. Des années plus tard, les descendants d'Aetius, fils d'Anthas, partirent comme colons de Trézène et fondèrent (apôikisan) Halicarnasse et Myndos en Carie » [II, 30, 9]). Peutêtre faut-il distinguer la lignée des descendants du fondateur (les Antheadai (nom troublant aussi), selon l'inscription de Samalkis, 1. 32) de la "lignée » des prêtres de Poséidon. Noter que les deux textes sont assez proches dans le temps. 
kata genos (1. 4), et le nom de chaque prêtre est suivi de son patronyme avec, en regard, le nombre d'années que dura sa prêtrise. La liste commence ainsi (A, 1-5) : [Poséidon] - Télamon fils de Poséidon 12 ans - Antidios fils de Télamon 27 ans - Hypérès fils de Télamon 9 ans - Alkyoneus fils de Télamon 12 ans - Télamon fils d'Antidios 22 ans... De façon "archaïsante ", la liste mêle ce que nous considérons comme de la fiction (mythe ou légende) avec le réel ou le rationnel. Débutant par l'oikiste de la cité, un personnage que nous qualifions de mythique, ayant un père surhumain, sur lequel circulent des histoires qui racontent comment cela s'est passé, la liste continue puis, à un certain moment, qu'en général nous sommes bien incapables d'identifier, apparaissent les noms de "vrais » prêtres, pour se terminer par le nom de celui qui détient, hic et nunc, le privilège de servir ce dieu : là, le nommé Politès qui le fut 27 ans. Une brisure de la pierre mise à part, et qui nous prive de nombreux noms, aucun hiatus, donc, entre le mythe et l'histoire ${ }^{36}$. Plus même. Certains usages onomastiques ont pour effet de brouiller les catégories. C'est ainsi qu'on voit apparaître dans la liste des noms «mythiques ». On s'y attendait, surtout dans la première partie : deux Alkyoneus, un Télamon, un Anthas, un Démétrios, un Dioskouridès, un Poseidonios. Certes, il n'est pas du tout interdit de penser que nous ayons affaire en cette occurrence à une "fabrication", mais les règles de la dévolution d'un sacerdoce à l'intérieur d'un "génos" peuvent s'accompagner d'une modification du nom de l'impétrant en cas de nécessité. Ainsi, dans le cas bien connu des noms de la prêtresse athénienne d'Athéna Polias (alternativement une Lysistratè et une Lysimachè) si une raison quelconque empêche celle qui doit prendre le sacerdoce de le faire, on doit imaginer qu'on changera le nom de celle qui viendra en second dans liste des possibles ${ }^{37}$. Archaïque aussi, l'absence fréquente de repère chronologique arithmétique. Fréquente, mais non générale : voir le Marbre de Paros, avec ses archontes et les durées de prêtrise de la liste d'Halicarnasse. La prêtrise de Télamon se mesure, et elle se mesure avec le même étalon que celle de Politès : 12 ans.

Pour reprendre le cas des textes littéraires et de leurs généalogies ${ }^{38}$, c'est par le thème et par la structure que ces récits parviennent à donner la sensation de la durée. Le thème, implicite et parfois explicite, ce sont les origines. Soit, dans la Bibliothèque, le cas d'Argos, cœur et centre de la Grèce, pour retrouver cet Agènor apparu tout à l'heure entre Libyè et Eurôpè.

D'Océan et de Téthys naquit un fils, Inachos, qui a donné son nom à l'Inachos, le fleuve d'Argos. D'Inachos et de Mélia, fille d'Océan, naquirent comme fils Phorôneus et Aigialeus. Aigialeus mourut sans enfant et toute la contrée fut appe-

\footnotetext{
36 Le total des années des prêtrises de la colonne de gauche s'élève à 395, celle de droite à 110 ans. R. DESCAT, l.c. (n. 34), à partir de la date présumée de 250 parvient à 645 av. n. è, et conclut que c'est «effectivement trop récent pour Télamon, fils de Poséidon lui-même ». Certes !

Voir mes observations dans DHA 16, 2 (1990), p. 85-86, prenant appui sur Gr. NAGY, « The naming of Athenian Girl », CJ 74 (1979), p. 360-364.

38 Sur le genre, voir les communications rassemblées par D. AUGER et S. SAÏD (éds), Généalogies mythiques, Paris, 1998.
} 
lée l'Aigialéia. Phorôneus, qui régna sur tout le pays appelé plus tard le Péloponnèse eut de la nymphe Télédikè, Apis et Niobé. Apis changea son pouvoir en tyrannie. Tyran brutal, il nomma le Péloponnèse l'Apia, d'après son propre nom, et mourut sans enfant, victime d'un complot... Il fut considéré comme dieu et appelé Sarapis. De Zeus et de Niobé (la première femme mortelle à laquelle s'unit Zeus) naquirent comme fils Argos et, selon Acousilaos, Pélasges : c'est, dit-on, d'après son nom que les habitants du Péloponnèse sont appelés Pélasges. Argos reçut la royauté de Phorôneus et appela le Péloponnèse Argolide, d'après son propre nom. Il épousa Evadnè, fille de Strymon et de Néaira et eut pour enfants Ekbasos, Péiras, Epidauros et Criasos, lequel reçut la royauté. D'Ecbasos naît Agènor, et d'Agènor Argos, qu'on appelle Panoptès « Celui qui voit tout » (II, 1, 1).

Ces textes insistent sur tous les commencements: l'Inachos, comme eau primordiale, Phorôneus, comme premier homme, Niobé, comme première partenaire "humaine» de Zeus. Tout vient, avec redondance, de Téthys et d'Océan : l'Inachos et Mélia. Dans l'identification des origines, la terre et l'eau reviennent partout avec insistance (on verra plus loin l'omniprésence de l'eau à Troie). La terre ? Il n'est que d'évoquer le cas d'Athènes, surtout, avec ses «terrestres » noms parlants répétés que sont Aktaios, Kranaos, Kranaè, Kranaichmè et son Erichthonios ${ }^{39}$. À Argos, c'est l'eau, ce sont les fleuves, celui qui entoure la terre, Océan, et puis l'Inachos et le Strymon. Et, pour faire bonne mesure, il faut des Adam-et-Ève: Phorôneus est le premier homme. Niobé la première femme aimée de Zeus. Les Pélasges, les premiers habitants. Il est remarquable qu'Eurôpè soit associée une fois dans les sources à Phorôneus. Ce Phorôneus est si important aux yeux des Argiens que l'un des premiers historiens, Acousilaos d'Argos, le qualifiait de " premier parmi les hommes»(FGrH 2 F 23a). Il descend d'Océan et Téthys, comme l'Eurôpè hésiodique. Il fut désigné par les dieux comme arbitre de la dispute entre Héra et Poséidon pour la possession du Péloponnèse et choisit Héra comme poliade (schol. Euripide, Oreste, 932). C'est lui qui apprit aux hommes l'usage du feu et à vivre en cité. Il ressemble en cela au premier roi d'Athènes, Kékrops. Eurôpè, alors, comme une d'Ève ? Dans cette scholie à Euripide ${ }^{40}$, le nom exact de cette Ève est Eurôps, et le couple enfante Niobé; ou bien cette Eurôps est la fille de Phorôneus et de Peithô.

\section{Comment ça marche?}

Soit un roi A. On donne sa fiche: d'abord, des noms : le sien, presque toujours parlant, et comment, d'après lui (le bothen de Photios), s'appelle le pays et puis, éventuellement, les noms de ses fils et filles; c'est la cellule A. La vraie question, c'est sa lignée, son génos au sens le plus étroitement parental du mot - les récits généalogiques ont la procréation au coeur de leur fonctionnement. Quels problèmes rencontre ce roi dans sa tâche principale :

\footnotetext{
39 Je me permets de renvoyer à mon article : « La liste des rois d'Athènes dans la Bibliothèque d'Apollodore. Histoire et politique ", in M.-M. MACTOuX et E. GÉNY (éds), Discours religieux dans l'Antiquité, Paris, 1995 (ALUB, 578), p. 209-240, repris avec dans Poikilia (1996), p. 37-53.

40 E. SCHWARTZ, Scholia in Euripidem 2, Berlin, 1887, p. 189.
} 
fournir à sa mort un roi B à la communauté. Puis c'est le roi B. Les disputes pour le pouvoir jouent le même rôle. Il s'agit d'expliquer comment on passe de la cellule $\mathrm{A}$ à la cellule $\mathrm{B}$. Fonctionnellement, le récit généalogique se résume à cet enchaînement.

La succession de ces cellules, suffit, comme en stratigraphie, à établir une datation - relative. C'est ainsi que l'on va compter en générations (depuis / avant Deucalion...). La datation relative dit qu'Eurôpè est fille de Phoïnix. Ou bien qu'elle est fille d'Agènor, que sa mère, c'est Téléphassa ${ }^{41}$ ou Kassiepéia ${ }^{42}$ ou Argiope ${ }^{43}$ ou Tyro ${ }^{44}$ ou Périmède ${ }^{45}$. Elle vient après. Si ce n'est pas le cas, si l'on sait que tel fils devient roi de telle cité alors que son père est vivant, on en déduit que ce fils doit être illégitime ${ }^{46}$.

Qualifiera-t-on aussi d'archaïque cette autre façon caractéristique d'exprimer l'épaisseur du temps, qui relève de ce que l'on pourrait appeler son aspect? Cette épaisseur est rendue sensible au lecteur par des modifications progressives des comportements, de plus en plus «humains » (on naît, par exemple, de moins en moins «tout seul» du $\mathrm{sol}^{47}$, plus d'une fécondation de celui-ci, puis, de plus en plus, d'une femme, on n'enlève plus les femmes, on les épouse). Les personnages adoptent au fil des cellules les mœurs qu'au temps $t$ on considère comme celles de la «civilisation ». Cela restitue une image très positive - positiviste même - du temps, une lecture qui se trouve peut-être à l'origine de notre temps historique. Tout contribue à cette marche en avant: la mention successive de l'arrivée des dieux, de l'invention des céréales, du vin, du mariage, de la culture de l'olivier, de la disparition des monstres de la surface de la terre, de la naissance de l'artisanat - tout cela étant aussi objet d'une datation relative. Discrète, cette accumulation des notations de progrès, l'élimination des vieilles peurs, concourt à une représentation affinée du temps historique : point de sinusoïde ici, point de temps cyclique : un vecteur constamment tendu vers un présent meilleur.

On l'a compris, si le récit généalogique est inscrit dans le passé, sa raison d'être, c'est le présent. C'est lui qu'il s'agit de comprendre, c'est lui qu'il contribue à justifier - on verra qu'il en va de même de la géographie.

\footnotetext{
41 Moschos, II, 42 (la graphie donne Téléphaassè); elle porte parfois un autre nom, Tèléphè chez Stéphane de Byzance, s.v. "Thasos » (éd. A. Meinecke, 1849, p. 306) et la scholie à Euripide, Phén., 5 (éd. SchwarTz).

${ }^{4}$ Scholie T à Iliade XIV 321, cf. Eustathe, Com. P. 939, 34, comme épouse de Phoïnix.

43 Hygin, Fab., 178, 1, comme épouse d'Agènor.

44 Jean d'Antioche (Fragmenta Historicorum Graecorum, IV, P., 1866), fr. 6, 15, comme fille du héros éponyme Tyros et épouse d'Agènor.

45 Asios de Samos, fr. 7 (A. BeRnABÉ, Poetarum Epicorum Graecorum Testimonia et Fragmenta, Leipzig, Teubner, 1987, p. 127-130) (= Pausanias, VII, 4, 1, qui le cite souvent), fille d'Oineus, comme épouse de Phoïnix.

46 Voir ce que raconte Pausanias à propos d'Eurôps fils illégitime de Phorôneus et de la cité d'Hermione, selon Hérophanès de Trézène et d'après son propre raisonnement (II, 34, 4).

47 À l'aube de la Théogonie hésiodique, avant que Terre ne se couvre parthénogénétiquement de son amant, on naissait même de principes sans sexe, ainsi les enfants de Chaos, de Nuit.
} 
Pour qui s'intéresse plus aux mécanismes mentaux qui président à une production imaginaire, qu'à une éventuelle réalité - même si l'on reste attentif à sa manifestation -, on peut aller plus avant. C'est cette vision même du temps présent qui, par un raisonnement de type inductif, fait imaginer un passé qui s'épuise en retour en une fabrication-justification de ce qu'on a sous les yeux. Aussi les généalogies sont-elles à la fois "étiologiques » et toujours à refaire $^{48}$. Et, dans ce travail de réinterprétation, le nom fournit le socle pérenne de la réflexion. Dans ces réélaborations, les oikistes, les nymphes éponymes engrossées par des dieux, les archégètes, les autochthones, voire les gègeneis ${ }^{49}$ n'ont certes pas grand-chose à craindre d'une nouvelle narration, et de l'intervention éventuelle de nouveaux acteurs : ces fondateurs font déjà l'objet de reconnaissance et de cultes héroïques dans les cités concernées. Dans ce cas, l'«anatomie » de ces histoires peut se trouver modifiée, mais cela n'est pas ici le plus important au regard de leur «physiologie». En effet, on ne saurait retracer de la même façon ce «progrès » linéaire en 200, qu'en 400, qu'en 600. Et ce facteur vient s'ajouter aux explications habituelles de la variabilité des mythes : à l'oralité, au fractionnement politique, il convient d'ajouter ce fait que 40 générations ont cherché à rendre compte de la réalité de leurs présents, en se reconstruisant des passés à l'aide d'autant de fictions, d'histoires des origines, explicatives in fine du monde vécu (et cela, tout en conservant, au moins pour partie, les vestiges des mêmes quêtes successives rendant compte des environnements contemporains successifs). Que donnerait, de ce point de vue, la comparaison d'un récit des origines de la France composé au $\mathrm{x}^{\mathrm{e}}$ avec un récit du XIx ${ }^{\mathrm{e}}$ siècle ? À Athènes, le discours généalogique du $\mathrm{IV}^{\mathrm{e}}$ siècle diffère de celui du $\mathrm{VI}^{\mathrm{e}}$ dans la mesure où, sur des bases imaginaires anciennes, il rend compte - sans que ce soit son objet avoué - des évolutions de la société.

Mais ce même raisonnement (ou un raisonnement très proche) peut être mené dans la synchronie. Il suffit pour obtenir une induction différente à partir d'un même matériau onomastique qu'il soit appréhendé à partir de différents lieux, différentes cités. De sorte que la variabilité n'est pas toujours affaire de temps, mais aussi d'espace.

\section{L'espace}

Commentaire du bic et du nunc, donc, le récit généalogique restitue aussi, et c'est son originalité et sa richesse, l'image de l'espace conçu. J'ai séparé les deux axes, mais le récit les confond: les mœurs d'aujourd'hui, les coutumes des peuples, leur organisation territoriale, la façon dont on pense qu'ils sont disposés les uns par rapport aux autres, leurs montagnes et fleuves et les mers, on peut aller jusqu'à parler de leur biotope, tout cela est le résultat

48 L'Asie Mineure hellénistique offre un beau champ à de multiples études de ces fabrications de passés. Deux bons exemples (Téléphos et Pergame; les ancêtres de Tarse) dans l'ouvrage de T.S. SCHEER, Mythische Vorväter. Zur Bedeutung griechischer Heroenmythen im Selbstverständnis kleinasiatischer Städte, München, 1993 (Münchener Arbeiten für alten Geschichte, 7).

${ }^{49}$ Je renvoie aux travaux de Poikilia, l.c. (n. 32). 
d'une histoire dont la généalogie est la matrice. Et puisque le temps historique s'ordonne en un progrès, il en va de même de la fabrication de l'espace qu'on a sous les yeux.

Mais, assez d'abstractions, reprenons des généalogies, celle d'Eurôpè et celle de la maison de Troie. Celle d'Eurôpè n'est pas une, en réalité. Fille de Phoïnix l'éponyme et roi des Phéniciens, elle est une des conquêtes de Zeus chez Homère. Mais pourquoi faire l'amour à Eurôpè, si ce n'est pour que, chez Hésiode, elle engendre des rois de Crète (elle épouse bien un Astérion, prince des Crétois, mais qui se contente d'élever ses enfants) ? Chez Hésiode, elle appartient aussi, en compagnie d'Asie, à l'exubérante descendance d'Océan et Téthys. Dans un récit anonyme, elle apparaît aussi comme l'épouse du premier homme $e^{50}$. Et puis, sous le même nom, une fille de Nil aurait été une des épouses de Danaos et lui aurait donné quatre filles ${ }^{51}$. Mais rien de plus explicite, je crois, s'agissant de géographie que cet extraordinaire morceau d'Andron où Océan, dans son "harem», a (successivement ou simultanément!) deux «épouses »: Pompholygè, avec laquelle il a Asiè et Libyè, et Parthénopè, avec laquelle il a Eurôpè et Thrakè ${ }^{52}$ ! Et voilà comment on vous établit une carte : des nymphes pour fabriquer des pays. Mais pas seulement. Par leur somme, un monde aussi, dont le centre de gravité se trouve aux alentours de la Crète.

Eurôpè, jouit de qualités spatiales indéniables. La Bibliothèque met aussi ce trait en valeur ${ }^{53}$.

Libyè eut de Poséidon deux fils, Bèlos et Agénor. Bèlos régna sur les Égyptiens... Agènor, parti en Phénicie, épouse Tèléphassa et engendre une fille, Eurôpè, et des fils, Cadmos, Phoïnix et Kilix... Zeus, saisi d'amour pour elle, prit la forme d'un aimable taureau à l'haleine de rose et, lorsqu'elle fut montée sur son dos, il l'emporta en Crète à travers la mer. Là, Zeus s'unit à elle et elle enfanta Minos, Sarpédon et Rhadamanthe... Quand Eurôpè disparut, son père, Agènor, envoya ses fils à sa recherche, en leur défendant de revenir avant de l'avoir retrouvée. Sa mère, Tèléphassa, partit aussi à sa recherche, ainsi que Thasos, fils de Poséidon ${ }^{54}$. Mais après avoir fait toutes les recherches possibles, comme ils étaient incapables de retrouver Eurôpè, ils renoncèrent à rentrer chez eux et ils s'établirent chacun de son côté, Phoïnix en Phénicie, Kilix au voisinage de la Phénicie. Tout le pays qui

50 Cf. p. 255 et note 40

51 Selon la Bibliothèque elle-même (III 1, 5).

52 FGrH 10 F 7 (éd. JACOBY), cité par une scholie à Eschyle, Perses, 188 (O. DÄHNHARDT, Scholia in Aeschyli Persas, Leipzig, 1894, v. 188). La date du témoignage comme la distinction géographique entre la Thrace et l'Europe sont intéressantes. Andron fixe une Europe un peu plus à l'ouest et au sud.

53 La Bibliothèque reste dans sa perspective généalogique. Le début de ce troisième livre fait ainsi la transition avec le précédent : "Maintenant que, dans cet exposé sur la lignée d'Inachos, nous avons présenté les descendants de Bèlos jusqu'aux Héraclides, continuons avec l'histoire d'Agènor » de la même façon qu'au début du livre II, nous avions : " Maintenant que nous avons présenté toute la descendance de Deucalion, continuons avec celle d'Inachos. »

54 Sans que les choses y soient bien claires, comme parfois chez lui, Stéphane de Byzance donne Tèléphè comme mère de Thasos (s.v. «Thasos » [éd. A. Meinecke, p. 306]), ce qui ferait quatre frères de même mère en quête de leur sœur. 
s'étend à côté du fleuve Pyramos, Kilix l'appela Cilicie, d'après son propre nom. Cadmos et Tèléphassa s'établirent en Thrace. Semblablement, Thasos fonda en Thrace la cité de Thasos et s'y établit... Eurôpè fut épousée par Astérios, prince des Crétois, qui éleva ses enfants (III, 1, 1-5).

Transcrivons cette succession de cellules en tableau généalogique.

\begin{tabular}{|c|c|c|c|}
\hline \multicolumn{4}{|c|}{ Libyè $\times$ Poséidon - LIBYE } \\
\hline \multicolumn{2}{|c|}{ Agénor $\times$ Tèléphassa - (PHÉNICIE $)$} & \multicolumn{2}{|c|}{ Bèlos - (ÉGYPTE) } \\
\hline Zeus $\times$ Eurôpè & Phoïnix - PHÉNICIE ${ }^{55}$ & Kilix - CIIICIE & Cadmos \\
\hline
\end{tabular}

\begin{tabular}{|c|c|}
\hline $\begin{array}{c}\text { Eurôpè } \times \text { Astérios }= \\
\underline{\text { Minos }}, \underline{\text { Sarpédon, }} \underline{\text { Rhadamanthe }-(\text { CRèTE })}\end{array}$ & (THRACE) - Thasos \\
\hline
\end{tabular}

Chaque cellule dit une région d'un monde qui s'est diversifié par rapport à celui d'Andron, et dont le cœur est quelque part au sud de l'Egée. Pour nous aider à mieux saisir ce qui est en jeu dans ces textes, et comme nous l'avons fait pour le temps, il est utile de mener ici une comparaison avec une autre généalogie mythique, celle des reines de Troie. C'est le nom que M. Broadbent a donné à sa reconstitution des données troyennes fournies pour l'essentiel par l'atthidographe Hellanicos ${ }^{56}$.

Elle a bien mis en lumière un des caractères de cette généalogie (p. 28) : son " isolement » exceptionnel par rapport à l'ensemble des récits généalogiques grecs, eux qui, comme elle dit, "sont inextricablement imbriqués ». Bien sûr, comme partenaire de Zeus, Électre fille d'Atlas, et mère de Dardanos, se rattache par ses sœurs à la vulgate panhellénique. Mais c'est si peu! Un indice de cet isolement de la grande famille troyenne, c'est le fait que si Hésiode fait de Laomédon le fils de Tithonos, en rapport avec Éos et en rapport avec Képhalos (Théog., 954), donc en connexion le reste du corpus généalogique, dans cette généalogie troyenne, Hellanicos en fait un fils d'Ilos. Un autre caractère frappant de cette généalogie, c'est son caractère d'inven-

\footnotetext{
55 Dans une version que contiennent les Fables d'Hygin, Phoïnix ne resta pas en Phénicie, mais "partit chercher [sa sœur] en Afrique et y resta; voilà pourquoi les Africains sont appelés Puniques » (178)!

Studies in Greek Genealogy, Leiden, Brill, 1968, p. 27-39 (avec ses tableaux III et IV). Livre inventif, parfois génial, souvent imprudent et discutable (voir le sévère, mais juste, comme on dit, compte rendu de W. DEN BOER dans Gnomon 43, 5 [1971], p. 469-479). Il est faible dans la plupart de ses tentatives de systématisation (cycle de mariages sur deux générations dans la généalogie troyenne, de trois générations dans celle de Bellérophon...) et d'application à la période historique, il est audacieux et innovant dans le traitement systématique des informations généalogiques. C'est le cas pour cette reconstitution de la généalogie troyenne fondée sur les fragments 4 F 19, 23, 24, 29 et 138-140 d'Hellanicos (complétés par quelques informations prises à d'autres sources) et que je ne remets pas en cause.
} 
taire géographique quasi systématique de la Troade. Détaillons un peu. Deux lignées :

1 - Celle qui vient de Zeus. De ses embrassements avec Électre fille d'Atlas naît Dardanos ${ }^{57}$. La Dardanie, une région, Dardania, une ville, les Dardaniens, les habitants de la Dardanie, les Troyens. Avec son épouse Batiéia, Dardanos aura pour enfants : deux montagnes, un garçon Idaios et une fille Idaia et le premier Ilos de la généalogie. Cette Idaia ou une autre ${ }^{58}$ est épouse de l'ancêtre de l'autre lignée, Skamandros ${ }^{59}$. La Batiéia ${ }^{60}$ épouse de Dardanos est ellemême fille de Teukros ${ }^{61}$, un dieu fleuve phrygien ${ }^{62}$. Un autre fils de Batiéia sera roi, c'est Érichthonios. Époux d'une Kallirhoè, il a pour fils Tros, fondateur d'Ilion (une cité aux temps historiques), la future Troie. Son emplacement jouxte celui de Dardania.

2 - Des embrassements de Skamandros avec Idaia, naissent des filles, Kallirboè - il en a deux, l'une épouse Érichthonios, l'autre Trôs - et Strymô. Voilà beaucoup d'eau! Fleuve principal de la région, le Skamandre est aussi un dieu $^{63}$ et c'est de ses amours avec l'Ida que naît ce joli ruisseau qui intervient deux fois comme partenaire : 1 - d'un vrai chthonien, Érichthonios, et 2 - de l'éponyme des Troyens, Tros. Quant à Strymô (parfois Strymon), elle ne peut être un fleuve puisque ceux-ci sont mâles, mais sa quasi-homophonie avec le nom de fleuves est frappante ${ }^{64}$. Trôs est fils d'une autre mère que Kallirhoè, c'est Astyoche. Et cette Astyoche ne dépare pas dans la famille, elle est fille d'un fleuve, le Simoeis; celui-ci, comme tous, est fils d'Océan et Téthys. Le fils de Trôs, c'est Ilos qui épouse une Batiéia fille de Teukros.

À partir d'Ilos II, les cours d'eau se font moins fréquents ${ }^{65}$, les régions ou les unités politiques aussi. Je note «seulement »Strymô, déjà rencontrée, comme épouse de Laomédon; et, à la même génération, le fait que l'épouse de Kapys (le père d'Anchise), Hiéromnémè, est une Naïade. À la génération de Priam, le nom d'une de ses épouses ou concubines, Arisbè, est vraiment très proche d'une cité historique de Troade, Aribé. Il y a de temps en temps des « retours» d'eau. Ainsi, le fait qu'Hécube, la reine de Troie, soit la fille d'un

57 Dans ce qui suit, je souligne les noms référents de territoires, montagnes, cités ou villes.

58 On sait que les généalogies grecques n’ont pas peur des répétitions (voir le cas de la liste des rois d'Athènes, avec ces Pandion I et II, ses Kékrops I et II, ses Érechthée I et II...)

59 J'adopte des caractères italiques pour les noms de cours d'eau.

60 Qui réapparaît comme épouse d'Ilos II.

${ }^{61}$ Un Teukros réapparaît comme père de l'épouse de Priam, Arisbè et comme fils de Télamon. La chronologie est toujours mise à mal par les homonymies : ainsi, chez Stéphane de Byzance, s.v. «Dardanos », la Dardanie se serait d'abord appelée la Teukride.

62 Le mémoire de maitrise de M. MOAL, Oi potamoi, Rennes, 2004, consacré aux dieux fleuves mérite d'être cité.

${ }^{63}$ Skamandre réapparaît sous la forme Skamandrios comme fils d'Hector et Andromaque.

64 Voir ci-dessus p. 251 le Strymon « primitif » d'Argos.

65 Observation qui nous ramène à la qualité du temps : comme dans les généalogies d'autochthones puis de gègeneis, où le progrès se marque par des modes de reproduction moins surnaturels, ici, les héros se font de plus en plus « humains ». 
dieu fleuve, le Sangarios. Enfin, la nymphe Oinônè qui donna naissance à Korythos, le fils d'Alexandros, était fille du dieu fleuve Kebren.

Parmi les lectures d'une telle "histoire", il y aurait à jouer avec le genre (car ces espaces sont sexués), mais je ne retiendrai ici que celle de la «fabrication » d'un espace; chaque cellule ajoutant une touche au tableau final de la Troade tout entière. Montagnes, villes, cités et, c'est l'originalité de cette région, les cours d'eau. Les rois de Troie se reproduisent avec des filles « humides », que le paysage leur fournit.

De la même façon, dans le récit généalogique de la Bibliothèque, cité plus haut, nous voyons le monde, à la fois, se raconter et se faire sous nos yeux. L'histoire à travers les engendrements, l'espace, à travers les noms et les pérégrinations. Dans un processus simple et compliqué de diversifications. Mais une histoire et, certes, non l'Histoire. D'abord parce qu'on n'en finit pas de réexaminer le présent, donc de réécrire le passé, un passé différent selon les cités.

\section{« Les Grecs ont-ils cru à leurs mythes?"}

Quand, cherchant à dépasser ces récits forcément chauvins, Hérodote entreprend un examen "rationalisant » de l'histoire et de la géographie de la Méditerranée orientale, et il se montre fort critique vis-à-vis de ces récits généalogiques. Les guerres entre Grecs et Barbares auxquelles il consacre son enquête trouvent chez lui des causes anciennes, mais humaines. L'histoire qu'il veut en construire n'est pas celle d'un désir divin, ni de fleurs, ni de parthénos, elle évitera de faire appel à des personnages divins mus par le psychisme qu'on leur prête. Donnant la parole aux sages perses, il attribue la première faute aux Phéniciens (les revoilà !). Venus en Grèce, ils enlevèrent un jour des femmes grecques qui se pressaient à la poupe de leurs navires pour faire emplette de marchandises du Levant (qui ne voit que le schéma est le même, avec un retournement de scénario !). Y figurait Io, la fille d'Inachos. En représailles, «certains Grecs... abordèrent en Phénicie... et ravirent la fille du roi, Eurôpè »" ${ }^{66}$. Quels Grecs ? Peut-être des Crétois (c'est ce que suppose Hérodote), peut-être des Argiens (à cause d'Io). Zeus, le désir, ont disparu. Restent la Phénicie, la Crète ou Argos, Io et Eurôpè comme enjeux; mais, comme le dit Hérodote, «à ce moment, on était à égalité » (une femme partout!). Il a fallu ensuite l'enlèvement de Médée, puis celui d'Hélène et, c'est alors que les Grecs portèrent la guerre en Asie. En voilà assez avec le casus belli.

Si les généalogies ne répondent pas à la question de l'éponymie d'une vaste terre: l'Europe, celle que nous connaissons, voyons ce qu'en pense Hérodote.

On vient de voir que la Crète est de nouveau au rendez-vous. Ce détail, en effet, ne laisse pas d'intriguer. Les généalogies précédentes nous laissaient sur

\footnotetext{
66 Histoires, I, 1-2.
} 
notre faim : on ne comprend pas comment on passe de ce fait : - elle fut grosse de trois héros crétois : Minos, Sarpédon et Rhadamanthe et épousa le roi de l'île, au fait d'être l'éponyme d'une autre vaste terre : l'Europe. Continuons avec Hérodote (I, 173). Dans une digression à propos de divers peuples du sud-ouest de l'Asie Mineure, en particulier les Lyciens, il développe ce qu'il sait de leurs origines. Dans ce cadre, il a une phrase qui ne manque pas à la fois d'intriguer et de fournir opportunément une réponse à la question précédente. Les Lyciens, dit-il, sont d'origine crétoise, et il justifie cette assertion par cette remarque «Toute la Crète était autrefois (to palaion) peuplée de Barbares »! Puis il enchaîne : "Les fils d'Eurôpè, Sarpédon et Minos, se querellèrent en Crète au sujet de la royauté... Minos chassa Sarpédon et ceux de son parti;... ils se rendirent en Asie dans la région dite Milyade... ». C'est la Lycie! Ainsi, la geste d'Eurôpè avec ses fils peuple le monde.

Europe $\times$ Astérios $=$ Minos, Sarpédon, Rhadamanthe - CRÈTE

\begin{tabular}{lll}
\hline Minos - CRÈTE & Sarpédon (avec sa mère) - LYCIE \\
\hline
\end{tabular}

Lisant cela, on peut se placer sur deux plans.

1. Dans l'examen de la matrice narrative qui rend compte de la «fabrication » du monde, on notera qu'aux yeux d'Hérodote, c'est de l'Europe que naissent des morceaux d'Asie.

2. On a beau jeu de mettre Hérodote en contradiction avec lui-même, lui qui, après avoir semblé rejeter les récits «mythologiques » et fait le silence sur Zeus, replonge dans ces mêmes récits pour la descendance d'Eurôpè. Mais n'est-ce pas un peu cuistre?

Il revient longuement sur ces explications en des pages polémiques fort instructives. "Je ris", quand je vois que beaucoup déjà ont dessiné des images d'ensemble de la terre, sans qu'aucun n'en ait donné un commentaire raisonnable; ils représentent l'Océan enveloppant de son cours la terre ${ }^{68}$, qui serait toute ronde comme si elle était faite au tour, et font l'Asie égale à l'Europe »" Ceux qui sont visés, ce sont certains concepteurs de pinakes, de cartes. Le premier cartographe de l'Antiquité, de l'opinion générale, est Anaximandre, disciple de Thalès. Il conçut un espace limité et mesuré, de forme générale ronde ou sphérique ${ }^{70}$. De même son élève, le fameux Hécatée, à la fois géomètre-urbaniste, géographe et généalogiste. Quant à Hérodote, après

\footnotetext{
${ }^{67}$ Sur ce rire, voir l'article de C. DARBO-PESCHANSKI, «Rire et rationalité : le cas de l'historiographie grecque », in M.-L. Desclos (éd.), Le rire des Grecs. Anthropologie du rire en Grèce ancienne, Grenoble, 2000, p. 203-214.

${ }^{68}$ Pour reprendre la note de Ph. E. LEGRAND à ce passage (CUF, p. 69), tel était l'avis d'Hécatée (FGrH 332 c).

Histoires, IV, 36. Sur tout cela, voir le chapitre 4 de Chr. JACOB, Géographie et ethnographie en Grèce ancienne, Paris, A. Colin, 1991.

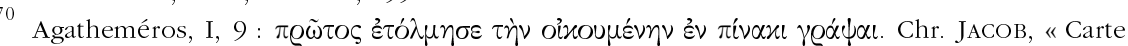
greche », in F. PronTEro (éd.), Geografia y etnografia nel mondo antico, Bari, 1983, p. 47-56.
} 
avoir configuré l'Asie et la Libye, il laisse de nouveau libre cours à son ironie. "J'admire donc ceux qui ont partagé et divisé le monde en Libye, Asie et Europe, alors qu'entre ces parties les différences ne sont point petites. Car, dans le sens de la longueur [celui des parallèles], l'Europe s'étend tout au long des deux autres ${ }^{71}$; et, sous le rapport de la largeur, il ne me paraît pas qu'elle puisse même être mise en comparaison $»^{72}$.

Sur le thème de la rationalisation, voyez les mots. Plus de Nymphes! En rupture avec tous les textes précédents, Europe, Libye, Asie sont ici pures abstractions géographiques. Sa définition de l'Europe s'oppose à celle d'Hécatée qui avait en gros la même que la nôtre. Hécatée divise notre ensemble Europe + Asie par le fleuve Tanaïs, c'est-à-dire le Don; c'est, grosso modo, notre limite ouralienne; la Sibérie est pour nous asiatique. Hérodote ne limite pas l'Europe vers l'est et il sépare le bloc nord, européen, d'un bloc sud, libyen + asiatique par le fleuve de Colchide, le Phase. Hérodote décrit ainsi sa Libye et son Asie ${ }^{73}$. «Quant à l'Europe, personne ne sait clairement si, vers le Levant et le Nord, elle est entourée d'eau; mais on sait que, dans le sens de la longueur, elle s'étend tout le long des deux autres parties ${ }^{74}$. Voilà donc bien, entre les trois parties d'un monde dont le cour est la Méditerranée orientale, ce qu'Hérodote appelait des différences «non petites ».

Mais, pour revenir sur le contenu du nom il faut maintenant citer, du même Hérodote, un passage passionnant.

Je ne puis non plus m'expliquer à quelle occasion la terre, étant une, a reçu trois dénominations distinctes, tirées de noms (epônymias) de femmes, et ont été fixées entre ces parties, comme lignes de démarcation, le Nil, fleuve d'Égypte, et le Phase de Colchide (d'autres disent le Tanaïs, fleuve du pays des Maiotes, et les détroits cimmériens) ${ }^{75}$; pas davantage, savoir les noms de ceux qui tracèrent ces démarcations, ni d'où (bothen) ils ont tiré les dénominations des parties. La Libye en effet, disent la plupart des Grecs, serait ainsi dénommée d'après Libyè, une

71 Annexant en quelque sorte la partie septentrionale de notre conception de l'Asie. Que l'Europe soit fondamentalement boréale, c'est ce que semble penser Hégésippe (cité par le scholiaste au Rhésos d'Euripide (29) (traduction de Fr. DiEZ DE Velasco, l.c. [n. 8], p. 124) : "Hégésippe dans ses Palleniaca (FGrH 391 F 3). Cadmos accompagné par Tèléphaè, la mère d'Eurôpè [passage corrompu] (se dirigea vers) - et apprit qu'Eurôpè commandait en Thrace; ils arrivèrent sur l'autre continent où Eurôpè sur tous exerçait le pouvoir, non pas la fille de Phoïnix, mais une femme du pays [abandonnée par son mari]; c'est à cause de celle-ci que tout le continent tourné vers Borée est appelé Europe. »

${ }^{72}$ Histoires, IV, 42. Hérodote ne connaît pas de limite septentrionale à son Europe (quid de la Thrace ?) alors que Libye et Asie sont limitées par des mers au sud.

${ }^{73}$ Sur la controverse d'Hérodote avec les Ioniens à propos de l'Europe, voir G. AMIOTTI, «L'Europa nella polemica tra erodoto e gli Ioni », in L'Europa nell mondo antico, o.c. (n. 9), p. $49-46$.

74 Histoires, IV, 45.

De nouveau, les notes de Ph. E. LEGRAND sont simples et claires : Hérodote conteste que le Nil forme la démarcation entre l'Asie et la Libye (II 16); que le Phase de Colchide (le Rion du Caucase) forme la démarcation entre l'Europe et l'Asie; quant au Tanaïs, c'est contre l'opinion d'Hécatée qu'Hérodote en a, opinion qui marquait là une séparation nord/sud. 
femme autochthone; l'Asie aurait pour éponyme la femme de Prométhée... ${ }^{76}$ Pour l'Europe, de même que nul ne sait si elle est entourée d'eau, on est sans lumière sur l'origine de son nom et sur celui qui le lui imposa, à moins de dire que le pays (chôrè) reçut le nom de la Tyrienne ${ }^{77}$ Eurôpè; elle aurait en ce cas été auparavant anonyme, comme les autres parties du monde. Mais il est certain qu'Eurôpè était originaire d'Asie, et qu'elle ne vint jamais dans ce pays que les Grecs appellent présentement l'Europe; elle vint seulement de Phénicie en Crète et de Crète alla en Lycie $^{78}$.

Nombre de nos questions sont celles d'Hérodote. C'est bien à propos du processus de nomination qu'il s'interroge. Il pose deux questions : qui a fait ça et quand? Le monde pourrait-il exister sans nom? Pourquoi ces noms sont-ils des noms de femmes? Nous ne comprenons pas mieux que lui pourquoi les récits ne lient pas Eurôpè à l'Europe-epeiros. Au moins à l'Europe d'Hérodote, une Europe qui ne comprend pas la Crète. Libyè est autochthone ? Soit. Asiè épouse de Prométhée. Admettons. Mais l'Europe ne devrait pas s'appeler Europe ! Pourtant, c'est le cas !

Dans les récits qu'Hérodote connaît et dont nous possédons les vestiges, dans son errance, et par l'entremise de sa progéniture, Eurôpè nomme, et, nommant, fait exister diverses régions de notre Méditerranée orientale, mais rien moins que l'Europe, ni aux yeux d'Hérodote, ni pour l'instant aux nôtres. D'ailleurs, à la fin de ce constat d'ignorance et après s'être gaussé des opinions communes, Hérodote termine son paragraphe par cette phrase, qui est renoncement à la connaissance rationnelle : «En voilà assez là-dessus; car, en cette matière, nous suivrons l'usage consacré. »

\section{De Grèce en Égypte et retour}

Qu'est-ce donc que l'Europe grecque ? Comment expliquer que la région qu'un Grec du $V^{e}$ siècle appelle ainsi porte ce nom ?

Nommer, c'est donner existence. Ou plutôt, inversement, un nom ne peut être vide d'objet. Hérodote cherche une rationalité "globale » dans des renseignements de nature différente. L'invention de ces généalogies spatiales est, nous le voyons bien, pure expression de l'idéologie. Plus précisément, dans une pensée entièrement vouée à une conception immanente du divin, en l'absence de dieu créateur, l'histoire des choses et celle des hommes vont main dans la main. Cosmogonie, théogonie et anthropogonie, même histoire. Il n'y a donc pas à s'étonner de ce qu'un grand texte mythographique comme la Bibliothèque mêle l'espace et le temps. Ce qui complique les choses en Grèce, c'est que, si nous retenons comme définition du système idéologique,

\footnotetext{
76 Mais les Lydiens s'opposent à cette identification disant que ce n'est pas l'Asiè de Prométhée qui aurait donné son nom à l'Asie, mais un Asiès, fils de Cotys fils de Manès... Comme quoi on n'en finit jamais avec cette pratique généalogique.

${ }_{78}$ Comme un ethnique.

78 C'est pourquoi la Lycie est une terre de Crétois (!), Eurôpè y a accompagné son fils Sarpédon
} 
qu'il est une projection d'aspirations, on choisira vite entre le singulier et le pluriel, car on ne voit pas à l'œuvre ici une aspiration, mais des aspirations diverses, démultipliées par l'émiettement politique.

\section{Une invention bovine de l'Europe}

Pour être bien sûr de saisir ce qui est en cause, il faut suivre encore une histoire, celle qui prend comme vecteur le trajet d'une vache ${ }^{79}$, un dernier morceau de généalogie, celle d'Argos.

Argos et Ismène, fille d'Asopos, eurent pour fils Iasos, qui, dit-on, fut le père d'Io... Alors qu'Io occupait la prêtrise d'Héra, Zeus la séduisit. Découvert par Héra, il la changea d'un attouchement en génisse blanche et jura à Héra qu'il n'avait pas eu de relations avec elle... Héra envoie alors un taon contre la génisse. Celle-ci gagna tout d'abord le golfe ionien, ainsi nommé à cause d'elle; ensuite, après avoir parcouru l'Illyrie et franchi l'Haimos, elle traversa le détroit qui s'appelait alors le détroit de Thrace et qui s'appelle maintenant, à cause d'elle, le Bosphore ("Passage de la Vache »). Elle s'en alla en Scythie et au pays des Cimmériens et, après avoir erré sur de vastes étendues de terre et traversé à la nage de vastes étendues de mer ${ }^{80}$, elle arriva en Égypte. Là, elle retrouve sa forme primitive et, sur les bords du fleuve Nil, elle met au monde un fils, Épaphos («l'Attouché ») (Bibl.II $1,5-8)$.

Facile de suivre le trajet de cette vache, elle laisse sa trace partout : éponymie du golfe d'Ionie, du Bosphore, et par quels détours elle gagne - dans le sens trigonométrique inverse - l'opposé géographique et l'antithèse de son monde restreint à la seule Argolide : l'Égypte. L'Argolide, comme fondatrice de l'Égypte! Une orientation centrifuge de l'hellénité ${ }^{-1}$. Toute l'histoire qui vient après, comme aussi tout l'espace (la concomitance des deux dimensions se confirme), se déroule, à travers toutes les créations-nominations, au rebours de ce premier exil.

Épaphos devient roi d'Égypte, épouse Memphis, la fille de Nil, et fonde, en lui donnant son nom, la cité de Memphis. Il a pour fille Libyè ${ }^{82}$, à qui la Libye doit son nom. De Libyè et de Poséidon, naissent les jumeaux, Agènor et Bèlos. Agènor partit pour la Phénicie et en devint roi, et là, fut à l'origine d'une vaste lignée... Bèlos reste en Égypte, en devient roi et épouse Anchinoè, fille de Nil. Il en a des jumeaux, Egyptos et Danaos... Bèlos établit Danaos en Libye et Egyptos en Arabie; ce dernier soumit en outre le pays des Mélampodes («Pieds Noirs»), qu’il appela <de son nom> Égypte. Des nom-

\footnotetext{
79 Sur le rôle de la vache dans ces mythes, voir J.M. DAvison, « Myth and Periphery », in D.C. PozZI et J.M. Wickersham (éds), Myth and the Polis, Ithaca / London, 1991, p. 54.

${ }^{80}$ Les vaches grecques nagent : voir l'épisode fameux de la génisse qui se présente volontairement au sacrifice des Cyzicéniens après avoir traversé un détroit (Plut., Lucullus, 10, 1).

81 Deux lectures du voyage d'Io sont à recommander, celle d'A. BonNAFÉ, «Texte, carte et territoire : autour de l'itinéraire d'Io dans le Prométhée », JS (1991), p. 133-193 et JS (1992), p. 334 et celle de Cl. Calame, Poétiques des mythes dans la Grèce antique, Paris, 2000, où l'on trouvera, p. 117-144, un traitement de l'histoire d'Eurôpè et d'Io.

${ }^{82}$ Plus d'autochthonie, on descend des Argiens par les femmes !
} 
breuses femmes qu'ils eurent, naissent à Egyptos cinquante fils et à Danaos cinquante filles. Lorsque plus tard ils se disputèrent le pouvoir, Danaos, craignant les fils d'Egyptos, construisit, sur les conseils d'Athéna, un bateau (il fut le premier à le faire), y mit ses filles et s'exila. (Bibliothèque, II 1, 10-12).

Ce tableau est complété par le récit de la quête des frères d'Eurôpè à travers le monde et des conséquences géographiques de leurs pérégrinations. Rappelons qu'unie à Zeus, en Crète, elle a donné naissance à Minos, Sarpédon et Rhadamanthe..

Quand Europe disparut, son père, Agènor, envoya ses fils à sa recherche, en leur défendant de revenir avant de l'avoir retrouvée. Sa mère, Tèléphassa, partit aussi à sa recherche, ainsi que Thasos, fils de Poséidon, ou bien, d'après Phérécyde, fils de Kylix. Mais après avoir fait toutes les recherches possibles, comme ils étaient incapables de retrouver Eurôpè, ils renoncèrent à rentrer chez eux et ils s'établirent chacun de son côté, Phoïnix en Phénicie, Kilix au voisinage de la Phénicie. Tout le pays qui s'étend à côté du fleuve Pyramos, Kilix l'appela Cilicie, d'après son propre nom. Cadmos et Tèléphassa s'établirent en Thrace. Semblablement, Thasos fonda en Thrace la cité de Thasos et s'y établi. (Bibl. III, 1, 3-4)

Tableau généalogique issu du texte de la Bibliothèque:

\begin{tabular}{|c|c|c|c|c|c|c|c|c|c|}
\hline & & & & & $\underline{\text { Zeus }} \times \underline{\text { Io }}$ & Nil & & & \\
\hline & & & & & Epaphos & Memphis & & & \\
\hline & & & & & & $\begin{array}{l}\text { Libyè } \times \\
\text { Poséidon }\end{array}$ & & & \\
\hline $\begin{array}{l}\text { Arès } \times \\
\text { Aphrodite }\end{array}$ & & & & & $\begin{array}{l}\text { Agénor } \times \\
\text { Tèléphassa }\end{array}$ & & & $\begin{array}{l}\text { Bèlos } \times \\
\text { Anchinoè }\end{array}$ & \\
\hline \multirow[t]{2}{*}{$\begin{array}{r}\text { Harmonie } \\
\times\end{array}$} & Cadmos & Phoïnix & Kilix & Thasos & $\begin{array}{l}\text { Eurôpè } \times \\
\text { Zeus et } \\
\text { Astérios }\end{array}$ & & Danaos & Céphée & Aigyptos \\
\hline & & & & Minos & Sarpédon & $\begin{array}{l}\text { Rhadaman- } \\
\text { the }\end{array}$ & $\begin{array}{l}50 \\
\text { filles }\end{array}$ & & 50 fils \\
\hline
\end{tabular}

Tentative de représentation spatiale :

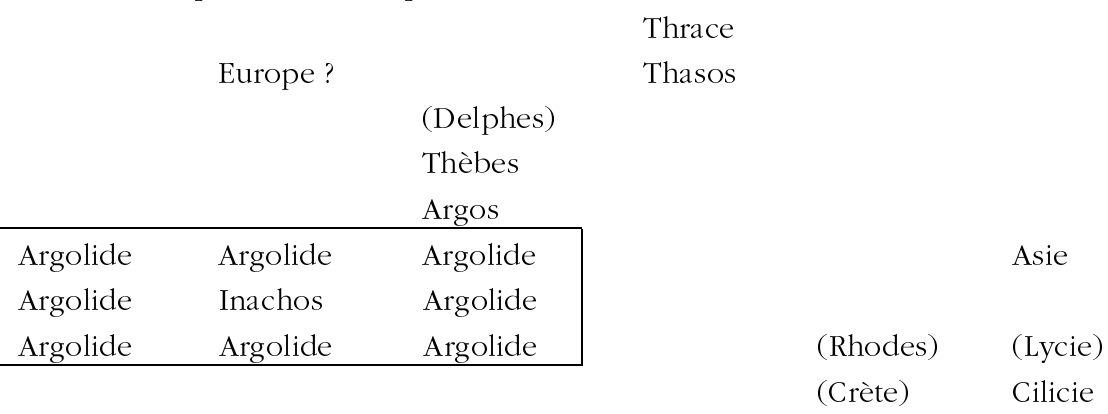

Libye Égypte

Phénicie 
Ainsi, la quête d'Eurôpè dans le sens trigonométrique cette fois dessine une géographie de la Méditerranée orientale. L’analyse structurale met en évidence les oppositions binaires - c'est bien le cas ici : la figure d'Io, la vache, centrifuge, s'oppose à celle d'Eurôpè, centripète. Elle-même, et par descendance interposée, quitte cette étrangère périphérie du monde et gagne des terres nouvelles. Au début de ce mouvement, à chaque fois, les errances de fils d'Europe et d'elle-même, définissent et délimitent des territoires périphériques de l'Hellade (Cilicie, mais aussi Lycie et Carie). À chaque fois, le vocabulaire utilisé est celui de la fondation coloniale. Mais le tournant fondamental survient avec Cadmos.

Lorsque Tèléphassa mourut, Cadmos l'ensevelit et, après avoir reçu l'hospitalité des Thraces, il alla à Delphes s'enquérir du sort d'Eurôpè. Le dieu lui dit de ne plus s'occuper du sort d'Eurôpè mais de se laisser guider par une vache et de fonder une cité là où elle tomberait d'épuisement (Bibl. III, 4,1$)^{83}$.

La lecture la plus géographique de cet épisode, c'est, évidemment, que le voilà vraiment en Europe et que, par conséquent, sa quête n'a plus de raison d'être, c'en est fini de cette Eurôpè introuvable - on peut dire, maintenant, cette Europe. Les trois villes de Macédoine et du Pénée, la signification géographique à donner aux passages de l'Hymne à Apollon (supra, p. 246), les passages d'Hérodote (VI, 43; VII, 8) où les Perses, ayant franchi l'Hellespont, «se mettent en marche à travers l'Europe, en marche pour Érétrie et Athènes", et où Xerxès promet de "conduire l'armée à travers l'Europe », tous ces indices suffiraient déjà à définir cette Europe comme équivalente à cette épeiros qui va de la Thrace au golfe de Corinthe. Xerxès confirme cette «frontière ». " $\mathrm{Si}$ nous subjuguons, dit-il, ces gens (les «Européens »!) et leurs voisins, les habitants du pays de Pélops le Phrygien (!), nous étendrons les limites de la Perse jusqu'à celles du ciel de Zeus! ». Il n'est jusqu'à Justin (VII, 1) (à propos des terres à l'ouest de la Thrace : Ex alio latere in Europa regnum Europus nomine tenuit) et Ammien Marcelin (XXVII, 4,12 ) (qui localise la province romaine d'Europe au sud de Constantinople) pour ajouter foi à cette localisation en Grèce septentrionale ${ }^{84}$.

Mais revenons à Cadmos. "Muni de cet oracle, il fit route par la Phocide, et lorsqu'il rencontra une vache des troupeaux de Pélagon, il la suivit. Elle traversa la Béotie et se coucha. Là Cadmos fonda (ktizein) une cité, la Cadmée, à l'endroit où se trouve maintenant Thèbes ${ }^{85} »$ (22).

Mais... ça serait trop beau et déjà trop vite "civilisé ». Il faut encore des échecs. Souhaitant sacrifier sa vache-guide à la déesse qui l'a aidé : Athéna,

\footnotetext{
83 À partir de là, les récits d'Apollodore et des scholies $\mathrm{AD}$ au Catalogue des vaisseaux de l'Iliade (II, 494), citant à la fin les Boiotika d'Hellanicos (FGrH 4 F 51), sont remarquablement semblables (voir la mise en parallèle par Vian, o.c. [n. 8], p. 21-22, dans sa présentation des sources).

84 GOMmers, l.c. (n. 10), p. 32, cite aussi un diocèse byzantin nommé Europa sur la côte orientale de la Thrace, mais sans donner sa source.

${ }^{85}$ Même histoire (à des détails intéressants près) chez Hellanicos (FGrH 4 F 51 = scholie Iliade II 494 [éd. Dindorf]). Source traduite chez CARRIÈre - MASSONIE, p. 217.
} 
ses compagnons sont envoyés à la recherche d'eau pour le sacrifice; ils sont tués par le dragon qui défendait la source Arès. Cadmos tue le dragon. Athéna lui conseille alors de semer les dents du dragon. Il en naît les «Semés », qui s'entretuent, à l'exception de cinq d'entre eux. Ce sont des nés du sol.

Les récits généalogiques jouent sur une complémentarité/opposition entre deux thèmes, celui des aventures océaniques et de la colonisation, avec la figure complémentaire de la nymphe raptée/séduite, en tout cas engrossée par un divin personnage, et celui de l'autochtonie, de la naissance du sol même. Il peut souvent y avoir redondance. Il faut à la fois le fondateur, l'éponyme et le gègenès ${ }^{86}$. Eurôpè joue deux rôles : fondatrice par ses embrassements divins, et éponyme, bien sûr. Les éponymes sont souvent femmes, on l'a vu. Car c'est du désir divin que tout est venu. Il faut la nymphe pour tout enclencher du désir divin qui fait des enfants porteurs de noms géographiques. La nymphe est narrativement un prétexte. Mais, ces noms eux-mêmes, croira-t-on qu'ils existent par l'histoire ? Je crois que les Grecs eux-mêmes en ont eu l'illusion (même Hérodote y succombe), et du haut de notre rationalisme nous ne saurions douter que l'Europe a précédé Eurôpè. Mais ce que nous pensons importe moins que ce qu'ils pensaient, alors j'y reviens une dernière fois.

Après expiation de sa faute envers Arès, Cadmos reçoit la royauté, et Zeus lui donne en mariage Harmonie la divine, fille d'Arès et Aphrodite. Noces inouïes auxquelles participent les dieux. Comme cadeau de noces, elle reçoit un merveilleux collier, fabriqué par Héphaïstos. Et qui le lui donne ? Eurôpè, sa belle-sour. Dans cette succession d'événements, fondation de la cité, sacrifice de la vache et promesse d'une nombreuse descendance, certains ont vu la convergence des trois fonctions indo-européennes. J'y verrais plus simplement le renfermement sur elle-même d'une carte du monde fort chauvine où les petits cantons de la Grèce se considèrent à la fois comme le centre du monde et à l'origine de celui-ci. Une conception où cette mère des peuples s'est conçue topographiquement comme une anti-Égypte. Un scénario où, si un mouvement civilisateur vient bien de Phénicie et d'Égypte, c'est par la médiation d'Io que tout cela est possible : Argos a fourni aux terres extrêmes l'instrument qui, en retour, redéfinit la Grèce.

Pierre BRULÉ

Crescam - Université de Rennes 2

86 Voir les études de L. PIOLOT, «Autochthones et allochtones, le nécessaire mariage des genres », Poikilia (1996) p. 55-77, de M. Cochet et d'E. ChEMinel, dans le même numéro, citées à la note 32 . 